J. Lake Sci. (湖泊科学), 2022, 34(1): 18-37

DOI 10. 18307/2022. 0104

(c) 2022 by Journal of Lake Sciences

\title{
湖泊湿地水文过程研究进展”
}

谭志强 ${ }^{1}$, 李云良 ${ }^{1}$, 张 奇 $^{1}$, 郭宇菲 ${ }^{2}$, 王晓龙 ${ }^{1 * *}$, 李 冰 $^{1}$, 万荣荣 ${ }^{1}$, 王殿常 ${ }^{3}$, 吴兴华 ${ }^{3}$

(1: 中国科学院南京地理与湖泊研究所,中国科学院流域地理学重点实验室,南京 210008)

(2: 中国科学院大学, 北京 100049)

(3:中国长江三峡集团有限公司, 北京 100038)

摘 要: 湖泊湿地是世界上最重要的生态系统之一, 在调蓄洪水、净化环境、保护生物多样性以及为人类提供淡水和食物 等方面发挥着不可替代的作用. 然而,受气候变化和人类活动叠加影响,湖泊湿地水文过程发生了剧烈变化, 湖泊湿地面 临着面积萎缩、质量下降和服务功能退化等风险. 本文总结了原位观测、数值模拟和遥感技术在获取湖泊湿地关键水文 要素方面的优势及不足; 从辩证的角度探讨了气候变化和人类活动对湖泊湿地水文过程的双重影响; 结合洪水和水文连 通性等研究热点分析了水文过程的典型表现形式; 从正反两方面揭示了湖泊湿地植物、动物和水质对水文过程改变的响 应. 本研究最终提出未来应该将谣感技术与数值模拟方法相结合,建立“多目标一多要素一多尺度一多过程”的湖泊湿地监 测体系; 定量评价多维度水文连通的转化方式及其对生态系统的阈值效应; 加强研究地下水驱动下湿地植被演变的非线 性动力学机制; 综合考虑栖息地的面积和质量评价水鸟种群的弹性力和恢复力,为湖泊水位调控和退化湿地的恢复提供 科学依据.

关键词: 湖泊湿地;水文过程;数值模拟; 遥感;洪水;水文连通

\section{Progress of hydrological process researches in lake wetland: A review*}

Tan Zhiqiang ${ }^{1}$, Li Yunliang ${ }^{1}$, Zhang Qi $^{1}$, Guo Yufei ${ }^{2}$, Wang Xiaolong ${ }^{1 * *}$, Li Bing $^{1}$, Wan Rongrong ${ }^{1}$, Wang Dianchang $^{3} \& \mathrm{Wu}$ Xinghua ${ }^{3}$

(1: Key Laboratory of Watershed Geographic Sciences, Nanjing Institute of Geography and Limnology, Chinese Academy of Sciences, Nanjing 210008, P.R.China)

(2: University of Chinese Academy of Sciences, Beijing 100049, P.R.China)

(3: China Three Gorges Corporation, Beijing 100038, P.R.China)

Abstract: As one of the most important ecosystems in the world, lake wetlands are irreplaceable in flood regulation, environment decontamination, biodiversity conservation, and in the provision of freshwater and food resources. However, lake wetlands hydrological processes have changed drastically as a result of anthropogenic activities and climate change in combination, evidenced by shrinking wetland areas, declining wetland quality, and degraded wetland service functions. Here we summarized the merits and drawbacks of field observations, numerical simulations and remote sensing in deriving key hydrological elements of lake wetlands. The dual effects of human and climate on hydrological processes were discussed dialectically, and typical forms of hydrological processes were analysed incorporating the current hotspot flood and hydrological connectivity issues, and both positive and negative responses of plants, animals and water quality to changing hydrological processes were reviewed. In the forthcoming years, a combination of remote sensing and numerical simulation will lead to a "multi-objective, multi-factor, multi-scale and multi-process" lake wetland monitoring system. Based on extensive observational data, the conversion paths of multi-dimensional hydrological connectivity and their thresholding effects on ecosystem will be quantified. The investigation of nonlinear driving mechanisms behind wetland vegetation-groundwater dy-

* 2021-09-02 收稿;2021-10-09 收修改稿.

国家重点研发计划项目 (2019YFC0409002)、国家自然科学基金项目 (41801080,42171104)、江苏省自然科学基金 项目 (KB20181103)、中国长江三峡集团有限公司项目 (201903144) 和测绘遥感信息工程国家重点实验室资助课题 (20R01) 联合资助.

** 通信作者;E-mail:wangxl@ niglas.ac.cn. 
namics will be strengthened. The elasticity and resilience of waterfowls' population will be evaluated considering both habitat area and quality. The ultimate goal is to provide a scientific basis for lake-level regulation and wetland restoration.

Keywords: Lake wetland; hydrological process; numerical simulation; remote sensing; flood; hydrological connectivity

湖泊湿地是发育在湖泊边缘, 即枯水期水深不足 $2 \mathrm{~m}$ 的部分, 并且总面积不低于 $0.08 \mathrm{~km}^{2[1]}$. 如果该湖 泊受潮汐影响,那么由于潮汐导致的盐度应该小于 $0.5 \%$,对于一些淤浅程度高的浅水湖泊,整体都属于湖泊 湿地 ${ }^{[1]}$. 湖泊湿地是一类广泛存在的湿地类型, 包括了《拉姆萨湿地公约》分类体系内的: 永久性淡水湖 $\left(>0.08 \mathrm{~km}^{2}\right)$; 季节性/间歇性淡水湖 $\left(>0.08 \mathrm{~km}^{2}\right)$; 永久性咸水/半咸水/碱性湖泊; 季节性/间歇性的咸水/ 半咸水/碱性湖泊和浅滩; 永久性咸水/半咸水/碱性沼泽/池塘; 季节性/间歇性的咸水/半咸水/碱性沼泽/ 池塘; 永久性淡水沼泽/池塘, 无机土壤上的池塘 $\left(<0.08 \mathrm{~km}^{2}\right)$ 、沼泽和湿地 ${ }^{[1]}$.

地表上大约 $90 \%$ 的液态淡水都储存在天然湖泊和人工湖泊中 ${ }^{[2]}$. 根据 GLWD ( global lakes and wetlands database), 全球湖泊和水库总面积约为 $2.7 \times 10^{6} \mathrm{~km}^{2}$, 占陆地总面积的 $2.0 \%$ (南极洲冰川和格陵兰除外). 全 球湿地面积约为 $0.8 \sim 1.0 \times 10^{7} \mathrm{~km}^{2}$, 占陆地总面积的 $6.2 \% \sim 7.6 \%$. 全球面积 $\geqslant 0.1 \mathrm{~km}^{2}$ 的湖泊达到甚至超过 150 万个; 面积 $\geqslant 0.01 \mathrm{~km}^{2}$ 的湖泊总数可能达到或超过 1500 万个 ${ }^{[3]}$ (图 1). 目前尚没有针对全球 “湖泊湿地” 分布面积的权威报道.

湖泊湿地生态系统有着区别于其他生态系统的水文过程和生物地球化学循环过程, 因此其提供的生态 系统服务也从一定程度上区别于其他生态系统类型 ${ }^{[4]}$. 主要体现为涉水的生态系统服务,包括供应服务 (如 淡水供应)、调节服务(如净水、洪水调节、气候调节)、支持服务 (如野生动物栖息地) 和文化服务 (如娱乐) 等,在保障全球水生态安全格局中占有重要地位 ${ }^{[5-7]}$.

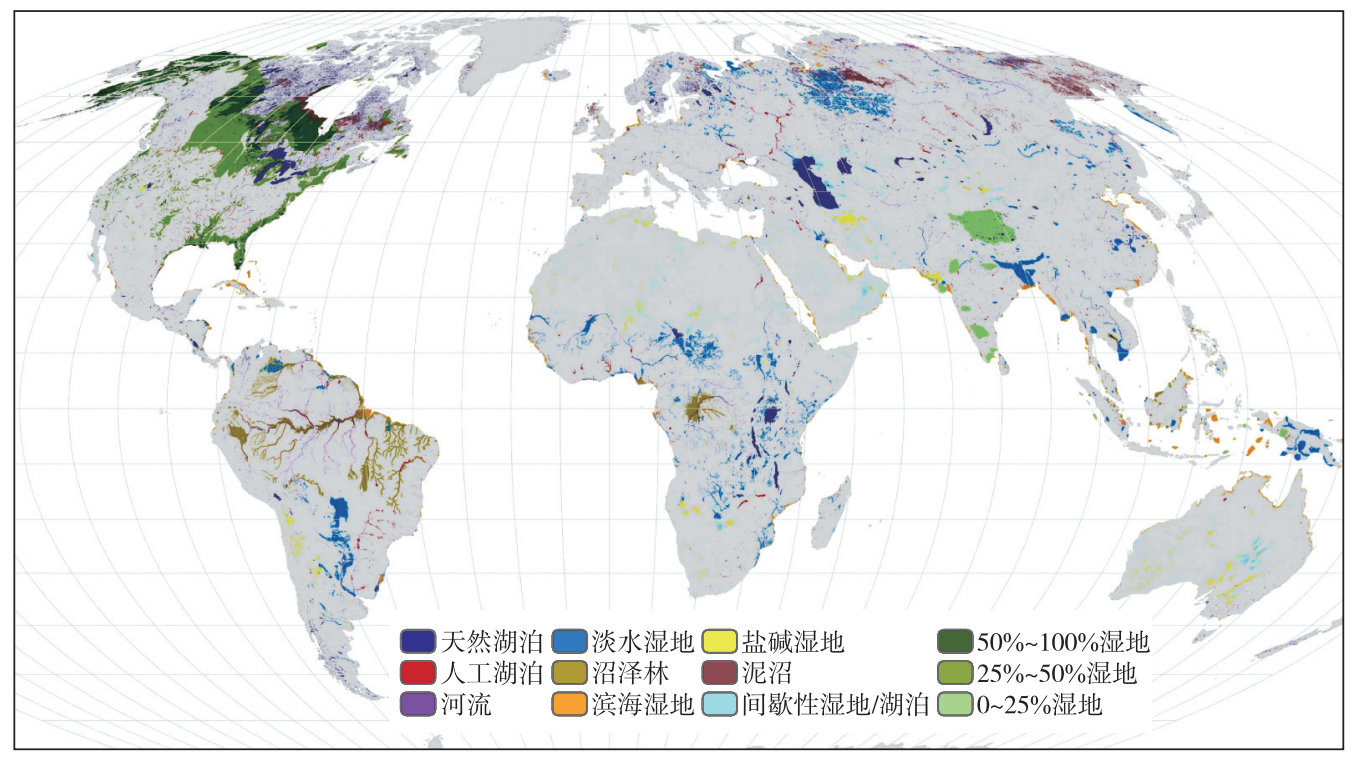

图 1 全球湖泊和湿地数据集

Fig.1 Global lake and wetlands database (GLWD)

湖泊生态系统是最容易受到威胁的水生生态系统之一 ${ }^{[8-9]}$. 受加剧的气候变化 ${ }^{[10]}$ 和不断增长的人口对 内陆水体的消耗 ${ }^{[11]}$ 叠加影响, 越来越频繁的干旱正威胁着这种脆弱的生态系统平衡 ${ }^{[12]}$. 旱生化是浅水湖泊 面临的主要问题 ${ }^{[13-14]}$. Davidson 调查了 189 份湿地面积变化的报告得出: 1900 年以来, 世界自然湿地损失的 比例约为 $54 \% \sim 57 \%{ }^{[15]}$, 其中包括湖泊湿地的加速萎缩或消失. 在中国, 从 1978 年到 2008 年, 总共损失了 $1.02 \times 10^{5} \mathrm{~km}^{2}$ 的湿地面积 ${ }^{[16]}$.

水文过程是水文要素在时间上持续变化或周期变化的动态过程, 特别是洪水泛滥的时机、范围、程度、 
持续时间及其变异性是湖泊湿地生态系统发育和演化的主要驱动力 ${ }^{[17-18]}$. 由于湖泊湿地范围广, 甚至难以 到达,变化程度和频率具有高度异质性,如何提高湿地水文要素监测的时空分辨率和准确性是湿地生态水 文研究一直以来所面临的挑战 ${ }^{[19-20]}$. 在全球气候变化和人类活动的双重影响下, 湖泊水文过程发生深刻变 化, 由此给湖泊周边人类社会和湿地生态系统造成的影响引起国际社会和专家学者的高度重视. 目前, 对于 湖泊湿地水文过程的驱动因素及其生态环境效应的认识往往存在片面性. 鉴于此, 以下从辩证的角度对湖 泊湿地水文过程的研究进展分 4 部分总结: 1) 关键水文要素的获取方法;2) 水文过程对气候变化和人类活 动的响应;3) 水文过程的典型表现形式;4) 水文过程的生态环境效应. 通过对湖泊湿地水文过程“是什么”、 “为什么” 和 “怎么样” 的系统综述, 补充对相关领域新问题和新方法的认识, 总结未来需要加强探索和创新 的科学前沿.

\section{1 关键水文要素的获取方法}

湖泊湿地水文要素主要包括地表水水位/水深、地下水水位、土壤含水量、水面蒸发、地表蒸散发和表层 水温等. 其中, 水位是水生植物赖以生存的浅水湖泊最重要的水文要素之一, 根据地表水位和观测点的地形 高程可计算水深,进而反映湿地蓄水量 ${ }^{[21]}$. 湖泊湿地通常河网密集, 下垫面自然属性具有高度空间异质性; 湖滨带地势平坦, 水流运动呈现非稳定性, 汇流特征复杂; 受高度动态的水位变化影响, 干湿交替频繁; 位置 相对偏远, 交通闭塞, 可达性差, 给湖泊湿地水文要素监测带来挑战. 目前, 湖泊湿地水文要素的获取方法可 以归纳为 3 种: 原位观测, 数值模拟和遥感技术.

\section{1 原位观测}

原位观测能够在不同时空尺度上捕捉更接近实际的水位、流量、水温、蒸发量和土壤含水量等水文要素 变化 ${ }^{[22-23]}$. 以水位观测为例, 按需求和实际观测场合可分为水尺直接观测和水位计自动测量. 目前国内外常 用的水位计主要包括浮子式水位计、声波式水位计和压力式水位计等,各自优缺点及适用环境详见表 1.

表 1 常用湿地水位观测设备性能比较

Tab.1 Performance comparison of commonly used wetland water level observation equipment

\begin{tabular}{|c|c|c|c|c|}
\hline 仪器类别 & 基本原理 & 优点 & 缺点 & 适用环境 \\
\hline 水尺 & $\begin{array}{l}\text { 人工 直 接 读 取 } \\
\text { 水尺 }\end{array}$ & 准确可靠, 无干扰 & $\begin{array}{l}\text { 需具备安装条件并在可视 } \\
\text { 范围,无法实时观测, 信息 } \\
\text { 化难度大 }\end{array}$ & $\begin{array}{l}\text { 具备水尺安装及观测条件的 } \\
\text { 任何水域 }\end{array}$ \\
\hline 压力式水位计 & $\begin{array}{l}\text { 通过水压 获 得 } \\
\text { 水位 }\end{array}$ & $\begin{array}{l}\text { 精 度 高, 安 装 } \\
\text { 方便 }\end{array}$ & $\begin{array}{l}\text { 受水温和泥沙等杂质的影 } \\
\text { 响, 稳定性稍差 }\end{array}$ & $\begin{array}{l}\text { 含沙量变化不大的低含沙 } \\
\text { 水域 }\end{array}$ \\
\hline 超声波水位计 & $\begin{array}{l}\text { 发 射 超声 波 测 } \\
\text { 水位 }\end{array}$ & $\begin{array}{l}\text { 适应面广, 安装 } \\
\text { 简便 }\end{array}$ & $\begin{array}{l}\text { 准确性受空气温湿度、水面 } \\
\text { 杂物及波浪影响 }\end{array}$ & $\begin{array}{l}\text { 岸边无垂直面且水位变幅不 } \\
\text { 大的水域 }\end{array}$ \\
\hline 雷达水位计 & $\begin{array}{l}\text { 发射电 磁 波 测 } \\
\text { 水位 }\end{array}$ & $\begin{array}{l}\text { 适应面广, 安装 } \\
\text { 简便 }\end{array}$ & $\begin{array}{l}\text { 准确性易受水面杂物及波 } \\
\text { 浪影响 }\end{array}$ & $\begin{array}{l}\text { 水面较干净、无频繁干扰的 } \\
\text { 水域 }\end{array}$ \\
\hline 浮子式水位计 & $\begin{array}{l}\text { 直接接触水面感 } \\
\text { 测水位 }\end{array}$ & $\begin{array}{l}\text { 性能稳定, 容易 } \\
\text { 维护 }\end{array}$ & $\begin{array}{l}\text { 容易因水位井遭受淤积而 } \\
\text { 失效 }\end{array}$ & $\begin{array}{l}\text { 适合建造水位井、河床稳定 } \\
\text { 的水域 }\end{array}$ \\
\hline
\end{tabular}

原位观测的时空范围取决于资源的可用性, 大多数通过现场测量的数据仅能提供一定时段、有限地理 单元内的水文和生态要素信息. 即使在合理大小的系统中, 监测也多集中于系统的特定部分, 无法对各要素 之间相互作用过程进行定量测量.

\section{2 数值模拟}

数值模拟以现有观测资料为基础, 能够满足不同时间分辨率和不同空间尺度水文过程研究的需要, 在 定量解析界面过程及预测关键水文要素的变化趋势方面具有显著优势. 从面向的生态系统划分, 国内外较 为熟知的湿地综合水文模型主要有 WETLANDS 模型 ${ }^{[24]}$ 、Jorge-MODFLOW 湿地模型 ${ }^{[25]}$ 、DRAINMOD 模 型 ${ }^{[26]} 、$ MIKE-SHE 模型 ${ }^{[27]}$ 和 HYDRUS-1D/2D 模型 ${ }^{[28]}$. 通常情况下, 湿地水文模型要考虑生物群落能量和结 构、生命史、养分循环、胁迫因子选择和体内平衡, 进而发展为生态水文模型. 从生态水文模型构建的空间结 
构来看, 可以分为集总式和分布式; 从耦合方式来看, 主要包括单向耦合和双向耦合两类; 从描述生态水文 过程的复杂程度来看, 可划分为概念性模型、半物理模型和物理模型 ${ }^{[29]}$ (表 2 ). 总体而言,集总式、单向耦合 以及概念性模型计算过程简单, 参数容易获取、适用于广泛的地理条件和水文情景研究. 而分布式、双向耦 合、半物理以及物理模型结构复杂, 参数难以获取, 需要专业的建模知识和丰富的数据积累. 此外, 水文要素 的时空动态影响湿地植被的生长竞争, 反之植被退化恢复影响界面水分循环; 三角洲在河道冲淤的影响下 不断演变, 需要在模型中对径流路径进行实时调整. 目前考虑水文过程与生态过程互反馈机制的双向耦合 模型仍有待发展和完善.

表 2 生态水文模型分类及特征

Tab.2 Classification and characteristics of eco-hydrological models

\begin{tabular}{|c|c|c|c|c|}
\hline $\begin{array}{l}\text { 分类 } \\
\text { 方式 }\end{array}$ & 类型 & 优点 & 缺点 & 代表性模型 \\
\hline \multirow[t]{2}{*}{$\begin{array}{l}\text { 空间 } \\
\text { 结构 }\end{array}$} & 集总式 & $\begin{array}{l}\text { 将流域作为一个整体单元, } \\
\text { 采用优势或均值处理非线 } \\
\text { 性自然过程中的变量或参 } \\
\text { 数,操作性强、较易获取 }\end{array}$ & $\begin{array}{l}\text { 未考虑或较少考虑流域内 } \\
\text { 部多种地理特征的空间异 } \\
\text { 质性,包含的物理参数缺乏 } \\
\text { 明确的物理意义 }\end{array}$ & $\begin{array}{l}\text { 大叶模型、DALTON 模型、DCA 模型、 } \\
\text { CASH 模 型、MASSMAN 模 型、 } \\
\text { PATTERN 模 型、PHILIP 模 型、 } \\
\text { RUTTER 模型、SPAC 模型、SWIMV2.1 } \\
\text { 模型、WAVES 模型和 SVAT 模型 }\end{array}$ \\
\hline & 分布式 & $\begin{array}{l}\text { 充分考虑状态和过程变量 } \\
\text { 的空间变化,采用有限差、 } \\
\text { 有限元等数值方法求解, 具 } \\
\text { 有较强的物理机制 }\end{array}$ & $\begin{array}{l}\text { 由于模型基于单元网格或 } \\
\text { 者子流域,需要更多的输人 } \\
\text { 数据和过程参数,给数据获 } \\
\text { 取和管理带来挑战 }\end{array}$ & $\begin{array}{l}\text { TOPOG-IRM 模型、TOPOG-Dynamic } \\
\text { 模型、CLM } 3.0 \text { 模型、CLM3.5 模型、 } \\
\text { DGVM 模 型、CLM-DGVM 模 型、 } \\
\text { RHESSYS 模型和 ECOHAT 模型 }\end{array}$ \\
\hline \multirow[t]{2}{*}{$\begin{array}{l}\text { 耦合 } \\
\text { 方式 }\end{array}$} & 单向耦合 & $\begin{array}{l}\text { 无需修改模型代码、保持水 } \\
\text { 文模型和生态模型的独立 } \\
\text { 完整性,每个模型组分能够 } \\
\text { 简单、有效地模拟详细的物 } \\
\text { 理过程 }\end{array}$ & $\begin{array}{l}\text { 生态模型和水文模型不能 } \\
\text { 共享陆面过程的模拟结果, } \\
\text { 无法实现信息数据的实时 } \\
\text { 传递; 二者时空尺度和共同 } \\
\text { 的敏感参数有所差别, 模拟 } \\
\text { 结果差异性大 }\end{array}$ & DHSVM 模型、SHE 模型和 VIC 模型 \\
\hline & 双向耦合 & $\begin{array}{l}\text { 可以定量模拟所有水文过 } \\
\text { 程的动态变化,物理机制健 } \\
\text { 全,模拟精度高 }\end{array}$ & $\begin{array}{l}\text { 模型的建立需要研究者同 } \\
\text { 时具备水文模型和生态模 } \\
\text { 型的专业技术背景,模型的 } \\
\text { 构建和验证所需数据量 } \\
\text { 较大 }\end{array}$ & COMSOL+Lotka-Volterra ${ }^{[30]}$ \\
\hline \multirow[t]{3}{*}{$\begin{array}{l}\text { 复杂 } \\
\text { 程度 }\end{array}$} & 概念性模型 & $\begin{array}{l}\text { 引进水分、养分胁迫系数计 } \\
\text { 算净第一生产力等生态要 } \\
\text { 素, 通过经验系数或土壤含 } \\
\text { 水量折算实际蒸散发量等 } \\
\text { 水文变量, 计算过程简单, } \\
\text { 参数容易获取 }\end{array}$ & $\begin{array}{l}\text { 对植被与水文要素之间的 } \\
\text { 关系描述缺乏机理性, 且大 } \\
\text { 多为松散耦合 }\end{array}$ & ECOHAT 模型和 SWIM 模型 \\
\hline & 半物理模型 & $\begin{array}{l}\text { 对植被生长及其与水文要 } \\
\text { 素之间的作用关系描述更 } \\
\text { 具有机理性; 将研究区离散 } \\
\text { 成半分布式或全分布式空 } \\
\text { 间单元, 具有较强的空间异 } \\
\text { 质性 }\end{array}$ & $\begin{array}{l}\text { 对光合作用等生态水文各 } \\
\text { 要素的简单化,致使其不能 } \\
\text { 较好地模拟水文要素对植 } \\
\text { 被生化过程的影响 }\end{array}$ & PNET- II 3SL 模型和 SWAT 模型 \\
\hline & 物理模型 & $\begin{array}{l}\text { 空间结构大多采用分布式, } \\
\text { 机理性较强; 不仅能够描述 } \\
\text { 冠层截留和土壤水运动对 } \\
\text { 植被生化过程的影响, 还能 } \\
\text { 模拟植被动态对降水再分 } \\
\text { 配的影响 }\end{array}$ & $\begin{array}{l}\text { 模型结构和计算过程复杂, } \\
\text { 涉及植被生理、形态等参数 } \\
\text { 众多, 部分参数难以获取 }\end{array}$ & $\begin{array}{l}\text { BEPS-TERRAINLAB 模型、MACAQUE } \\
\text { 模型、RHESSYS 模型和 VIP 模型 }\end{array}$ \\
\hline
\end{tabular}




\section{3 遥感技术}

遥感技术可以在短时间内获取大空间尺度湿地水文实况信息, 实现对地持续观测, 从而捕捉湿地水文 过程的周期性节律变化、突变及其发生的时间 ${ }^{[31]} .1972$ 年, 美国第一颗陆地资源卫星 (Landsat-1) 发射升空, 许多先驱性研究就此开展. 此后几十年, 湖泊湿地水文过程遥感监测在数据获取、技术方法和产品研制等方 面均取得了长足的进步 (图 2). 以传感器类型为例, 雷达测高数据具备全天时和全天候的特点, 例如 ICESat/ICESat-2 ${ }^{[32]}$ 、CryoSat-2 ${ }^{[33]}$ 、Jason-1/2/3 $3^{[34]}$ 、Sentinel-3 SAR ${ }^{[35]}$ 和 RADARSAT-2 ${ }^{[36]}$ 等常被用于水面提 取, 湖泊水位、水深监测及水量估算. 然而, 作为阵列单元的回波信号, 绝大多数雷达仅适用于对宽度大于 2 $\mathrm{km}$ 的水体的监测 ${ }^{[37]}$. 另外, 受仪器偏差影响, 扫描轨迹及脉冲位置无法保证前后观测的一致性 ${ }^{[38]}$. 微波遥 感数据虽然空间分辨率低, 但其亮温数据的获取不受天气条件的限制, 被广泛应用于土壤湿度和积雪厚度 反演 ${ }^{[39]}$. 但微波传感器重返周期一般比较长, 而且数据获取费用高, 解译难度大, 目前还多局限于个例的研 究. 光学传感器, 尤其是一系列中高分辨率多光谱遥感, 例如 Landsat TM/ETM+、SPOT、ASTER 和 ALOS 等为 精确识别和提取水体提供可能 ${ }^{[40-42]}$. 但是, 中高分辨率卫星因为扫描带宽小、重返周期长等原因在湖泊湿地 洪泛监测中往往受到限制 ${ }^{[43-44]}$. 与之相比, MODIS 和 AVHRR 等高时间分辨率的多光谱数据在中尺度和大 尺度洪泛监测中得到广泛应用 ${ }^{[45-47]}$. 然而, 其较粗的空间分辨率对于小型湖泊水面积测量结果的不确定性 达到 $-6 \% \sim 13 \%{ }^{[48]}$, 难以满足小尺度水文过程研究的需要 ${ }^{[49]}$.

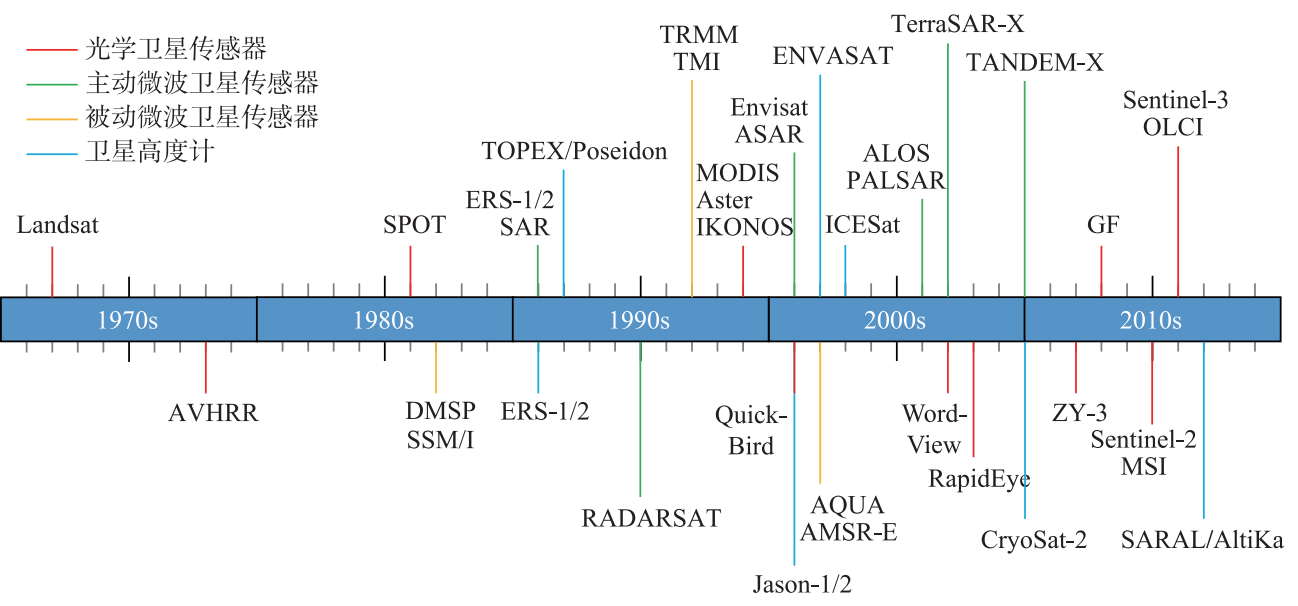

图 2 用于水面监测的常用卫星传感器发展历程

Fig.2 Development history of commonly used satellites/sensors for surface water detection

多源遥感数据融合方法为同时满足高时空分辨率的湿地水文要素监测提供了一个新的解决思 路 ${ }^{[43,50-53]}$, 主要包括间接策略和直接策略两种. 间接策略是利用较高分辨率的遥感数据 (如 Landsat) 分解较 低分辨率的遥感数据(例如 MODIS), 融合模型包括 STARFM ${ }^{[54]}$ 、半物理融合方法 ${ }^{[55]}$ 、STAARCH ${ }^{[56]}$ 、ESTAR$\mathrm{FM}^{[57]} 、 \mathrm{STDFA}^{[58]}$ 和 $\mathrm{ISTDFA}^{[59]}$ 等. 直接策略是辅助以土地覆盖/土地利用数据库等对 NDVI 进行像元分解达 到降尺度的目的, 例如 WLM ${ }^{[60]} 、$ STAVFM $^{[61]} 、 \mathrm{RMMEH}^{[62]}$ 和 NDVI-LMGM ${ }^{[63]}$ 等模型. 多源遥感数据融合作为 深人挖掘遥感大数据应用潜力的有效途径之一, 无论是直接策略还是间接策略都建立在一定假设的基础 上, 我们将在本文的展望部分进一步评述. 未来, 改进的融合模型及其对不同监测目标、不同地物属性和不 同空间尺度的适用能力有待深人研究.

\section{2 水文过程对气候变化和人类活动的响应}

随着经济持续增长和气候变化, 湖泊丰度已经减少, 湿地面积正面临萎缩风险 ${ }^{[21]}$. 例如, 全球变暖导致 水面蒸发加快, 长时间降水异常导致人流减少, 这些都很容易对湖泊水文、水生态和水环境产生连锁反应. 此外, 不可持续的土地利用和以利润最大化为唯一目标的水资源管理大大加剧了极端气候的影响. 但是, 水 
文过程对气候变化和人类活动的响应则表现为两面性.

\section{1 气候变化}

气候变化通过改变降雨、气温、辐射、风速以及洪水、干旱等水文极值的发生时间、频率和强度等影响湿 地水文过程和水文情势 ${ }^{[64]}$, 进而影响湿地生态系统服务, 如碳储存、支持生物多样性、提供野生动物栖息地 和净化水质 ${ }^{[42,65]}$. 湿地因其水源补给方式不同对气候变化的响应具有显著差异.

一方面,冬季积雪减少和早期融雪正通过改变径流的时间和流量影响高纬度和高海拔地区湖泊湿地的 水文过程 ${ }^{[66]}$. 例如, 2000-2015 年, 全球气候变暖引起的冰川冻土融水增加和降雨年代际增加导致青藏高 原内的湖泊面积扩张了 $4542.3 \mathrm{~km}^{2[67]}$. 1973-2017 年, 五大湖的平均冰覆盖范围( 12 月 1 日-4 月 30 日) 减 小了 $67 \%$, 其中密歇根湖的冰覆盖率下降了 $70 \%{ }^{[68]}$. 气温升高可能会推迟冬季冰的形成, 并在春季加速冰 的融化 ${ }^{[69]}$, 大多数冬季结冰的湖泊在未来可能保持无冰的状态. 另一方面, 在全球气温升高的背景下, 湿地 往往面临退化和萎缩的风险, 因为气温每升高 $3^{\circ} \mathrm{C}$, 需要降水量增加 $20 \%$ 才能补偿湿地生态系统因温度升高 而产生的旱化效应 ${ }^{[70]}$. 例如, 受气候变化影响, 北美大草原 ${ }^{[71]}$ 、土耳其图兹湖湿地 ${ }^{[72]}$ 、加拿大境内流域湿

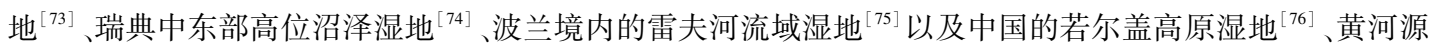
区湿地 ${ }^{[77]}$ 、松嫩平原扎龙湿地 ${ }^{[78]}$ 、白洋淀湿地 ${ }^{[79]}$ 等均出现了水位下降、水文周期缩短、干旱程度增强以及 部分水功能丧失等现象.

在过去的几十年里, 决定生态系统功能的关键气候因素变化非常快 ${ }^{[80-81]}$, 这种快速变化伴随着不同极 端天气的出现 ${ }^{[82-84]}$. 联合国领导的政府间气候变化专门委员会 ( IPCC) 发布的第六次评估报告第一工作组 报告显示, 北美、欧洲、澳大利亚、拉丁美洲众多地区、非洲的西部和东部、西伯利亚、俄罗斯和整个亚洲都在 经受高温极端天气(包括热浪) 的“考验”. 湖泊热浪可能会加剧湖泊长期变暖的不利影响, 改变湖泊的物理 结构和化学性质, 进而威胁到湖泊湿地的生物多样性以及湖泊湿地为社会提供的关键生态和经济效益 ${ }^{[85]}$. 《中国气候变化蓝皮书 $(2021)$ 》指出: 1961-2020 年, 中国极端强降水事件呈增多趋势, 极端高温事件自 1990s 中期以来明显增多. 高温、强降水等极端事件增多增强, 使降水变化区域间差异更加明显, 给湖泊湿地 水文过程带来深刻影响. 例如,2020 年, 长江流域和松花江流域地表水资源量均为 1961 年以来最多. 2005 年以来, 青海湖水位连续 16 年回升, 累计上升 $3.47 \mathrm{~m} ; 2016-2020$ 年水位加速上升, 2020 年已达到 $1960 \mathrm{~s}$ 初 期的水位 ${ }^{[86]}$. 相反, 受干旱影响, 1960 年以来华北平原最大的淡水湖泊湿地白洋淀水位降低, 水量减少, 面 积萎缩, 生物多样性减少 ${ }^{[87]}$. 极端气候事件引发的湖泊湿地极端水文过程及其对生态系统一大气之间碳交 换产生的负面影响需要更广泛的关注.

\section{2 人类活动}

人类活动同样以不同的方式影响着湖泊湿地水文过程. 一方面, 围湖造田、筑堤建圩、挖沟排水以及流 域水利工程等减少了地表径流的输人, 加速了湖泊的旱化进程, 降低了湖泊湿地调蓄洪水的能力. 北美大平 原是一个重要的农业区, 同时也是数百万河湖湿地的发源地 ${ }^{[88]}$. 大平原为美国供应大部分小麦、玉米和棉 花以及许多其他作物, 但草原转为农业用地极大地影响了湖泊湿地水文过程 ${ }^{[89]}$. 美国近几年失去的淡水湿 地中, 约 $98 \%$ 来自大平原 ${ }^{[90]}$. 截至 2007 年, 我国围层湖泊面积超过 $1.3 \times 10^{4} \mathrm{~km}^{2}$, 因围县消亡的天然湖泊近 1000 个. 号称“千湖之省” 的湖北目前只剩下 326 个湖泊,水面减少 $72 \%$. 昔日 “八百里洞庭” 从 $1940 \mathrm{~s}$ 末的 $4300 \mathrm{~km}^{2}$ 减少至 $2400 \mathrm{~km}^{2}$, 水面萎缩 $40 \%$, 水量减少约 $34 \%{ }^{[91]}$. 此外, 三峡水库蓄水显著改变了通江湖泊的 水文过程,叠加湖区采砂活动导致鄱阳湖等中下游湖泊秋季提前退水、枯水期延长以及枯水期水位降 低等 ${ }^{[92-93]}$.

另一方面, 退田还湖、筑坝拦蓄和跨流域调水等措施能够增加湿地面积, 有利于湿地水文功能的恢复. 例如, 1998-2003 年的退田还湖工程还鄱阳湖面积 $830.3 \mathrm{~km}^{2}$, 湖区增加蓄洪容积 45.7 亿 $\mathrm{m}^{3[94]}$, 还洞庭湖湿 地面积 $1390.84 \mathrm{~km}^{2}$, 增加蓄洪容积 80 亿 $\mathrm{m}^{3[95]}$; 三峡工程运行形成出露面积达 $437 \sim 446 \mathrm{~km}^{2}$ 的消落带, 造就 了一类特殊的湿地生态系统 ${ }^{[96]}$; 松嫩平原地区河湖连通工程引蓄洪水 21 亿 $\mathrm{m}^{3}$, 地下水水位抬升 $1 \mathrm{~m}$ 左右, 恢复和改善湿地面积 $2400 \mathrm{~km}^{2[97]}$. 黑龙江省政府制定了 $333.33 \mathrm{~km}^{2}$ 的三江平原湿地恢复计划, 从 2000 年到 2014 年,三江平原已经恢复了 $100 \mathrm{~km}^{2}$ 的洪泛区 ${ }^{[68]}$.

人类活动不仅从减少地表径流输人或拦蓄径流这两方面影响湖泊水文过程, 植树造林、森林砍伐、土地 
利用方式等也会影响流域水文循环和湿地储水空间,进而改变湖泊湿地的水文过程. 一些湖泊湿地可能对 气候变化具有相对的弹性. 但是,因为其他扰动的协同作用,由气候变化导致的负面影响经常表现为加剧的 趋势, 这些扰动往往都与人类活动密切相关. 如何管理和减少人类活动对生态系统的干扰, 减轻气候变化的 影响,促进生态系统的恢复进程是地球科学研究的永恒课题.

\section{3 水文过程的典型表现形式}

洪水是水文过程的一种极端表现形式, 伴随气候异常导致的极端水文事件在世界各地频发, 近年来有 关洪水的报道成为热点话题. 湖泊湿地作为天然蓄水库和水循环调节器, 在调蓄洪水、减轻洪涝灾害方面发 挥着极其重要的作用. 此外, 水文连通性是表征河流、湖泊和湿地之间水文过程的综合性指标, 通过调整河 湖水文连通可以优化水资源配置、改善生态环境和抵御水旱灾害等.

\section{1 洪水}

湖泊湿地通过蓄水、泄流和蒸散发调节洪峰大小以及洪峰的传播时间, 发挥着调蓄洪水的功能. 例如, 五大湖中苏必利尔湖最大蓄水量和最小蓄水量之差为 $5.76 \times 10^{5}$ 亿 $\mathrm{m}^{3}$, 平均调蓄水量达 9003 亿 $\mathrm{m}^{3}$. 休伦湖、 安大略湖、伊利湖和密歇根湖对夏季洪水的平均调蓄量分别为 4057 亿、576 亿、386 亿和 14 亿 $\mathrm{m}^{3}$. 洞里萨湖 是东南亚最大的天然淡水湖泊, 其流域降水和湄公河径流的季节性转换形成面积达 $1.06 \times 10^{4} \mathrm{~km}^{2}$ 的洪泛湿 地. 洞里萨湖在雨季水位上涨 7 $8 \mathrm{~m}$, 湖泊面积由 $2500 \mathrm{~km}^{2}$ 增加至 $1.3 \times 10^{4} \mathrm{~km}^{2}$, 调蓄洪水约 800 亿 $\mathrm{m}^{3[98]}$. 亚 马逊洪泛区分布着数量众多的子湖, 在调蓄流域洪水的过程中发挥着重要作用. 其中,Lago Grande de Curuaí (Pará) 湖在丰水年调蓄来自河流的水量就达 87 亿 $\mathrm{m}^{3}$, 是该湖泊最大水储量的 4.7 倍 ${ }^{[99]}$.

2020 年夏季, 我国南方遭受特大洪涝灾害, 长江中下游地区梅雨期持续时间较常年偏长 $23 \mathrm{~d}$, 平均降雨 量 $753.9 \mathrm{~mm}$, 比常年偏多 $168 \%$, 为 1961 年以来最多. 在本次洪水过程中, 洞庭湖城陵矶水位持续超警 $60 \mathrm{~d}$, 其中 $18 \mathrm{~d}$ 人湖流量大于出湖流量, 共计调蓄洪水 62.35 亿 $\mathrm{m}^{3[100]}$. 鄱阳湖区运用 185 座单退圩堤接纳洪量约 26.2 亿 $\mathrm{m}^{3}$, 有效降低了鄱阳湖水位 $0.35 \mathrm{~m}^{[101]}$. 两个大型通江湖泊在应对 2020 年中国南方特大洪灾中发挥 了关键作用 (图 3).

\section{2 水文连通性}

随着湖泊湿地水文过程研究的发展, 水文连通性“hydrological connectivity”引起广泛关注 ${ }^{[102-103]}$. 水文连 通性是指以水为介质的物质、能量及生物在水文循环各要素内或各要素之间的传输过程, 对河湖洪泛湿地 的水量平衡, 泥沙冲淤, 水鸟、鱼类、浮游藻类和大型底栖动物的生物量及生物多样性维护等至关重 要 ${ }^{[104-105]}$. 根据连通主体和水量交换关系的不同, 可以把水文连通划分为 3 个空间维度, 即沿水系流向的纵 向连通、水系与漫滩之间的横向连通和河湖地表水与地下水之间的垂向连通 (图 4). 水文连通性减弱是全 球河流、湖泊湿地面临的一个主要威胁 ${ }^{[106]}$.

建坝等基础设施建设是湖泊湿地水文连通性变化的重要原因. 目前全球已建大坝数量估计超过 5 万 座, 计划和在建大坝有 3600 座 ${ }^{[107]}$. 仅亚马逊流域, 在建和规划中的大坝项目就超过 400 座 $^{[108]}$. 大坝建设破 坏了湖泊湿地水文过程的天然节律, 导致河湖换水周期延长, 下游径流量减少, 湿地淹没深度和历时增加 等, 给湖泊水环境和湿地生态带来重要影响. 例如, 1950-1970 年间, 长江流域大建节制闸, 绝大多数湖泊失 去了与长江的天然联系, 水文连通性急剧减弱, 使支撑长江鱼类生存的有效湖泊面积减少了 $76 \%$, 以鱼为饵 料的白鳍豚、江豚种群数量锐减 ${ }^{[109]}$. 2003 年以后, 三峡工程运行改变了长江与鄱阳湖的连通关系 (包括长 江对鄱阳湖的“拉空”、“顶托” 和“倒灌” 作用等), 并由此引起鄱阳湖湿地高滩地中生植被退化, 水陆过渡带 湿生、挺水植被优势度降低, 低滩地沉水植被向退水方向演替等 ${ }^{[18]}$, 生长季的平均地下水埋深变化是湿地植 被格局演变最重要的影响因素 ${ }^{[110]}$. 由此可见, 横向、纵向水文连通与垂向水文连通之间存在着密切的关 联性.

湖泊湿地是地表水一地下水垂向连通非常活跃的区域,削弱的横向水文连通性可能会减少垂向水文连 通,导致湿地地下水位下降 ${ }^{[6]}$. 地表水一地下水之间的垂向连通不仅决定了界面水分交换通量,对盐分、潜流 层生物迁移等也有重要影响 ${ }^{[111]}$. 尽管国内外在地表水一地下水交互作用方面取得了大量研究进展, 但受原 位条件约束, 饱和一非饱和带的土壤水、地下水采样困难, 相关地质背景资料和经验不足, 加上缺少量化指标 
和评价工具, 考虑垂向连通性及其与其他维度连通性的交互关系研究仍面临着很大挑战 ${ }^{[112]}$.
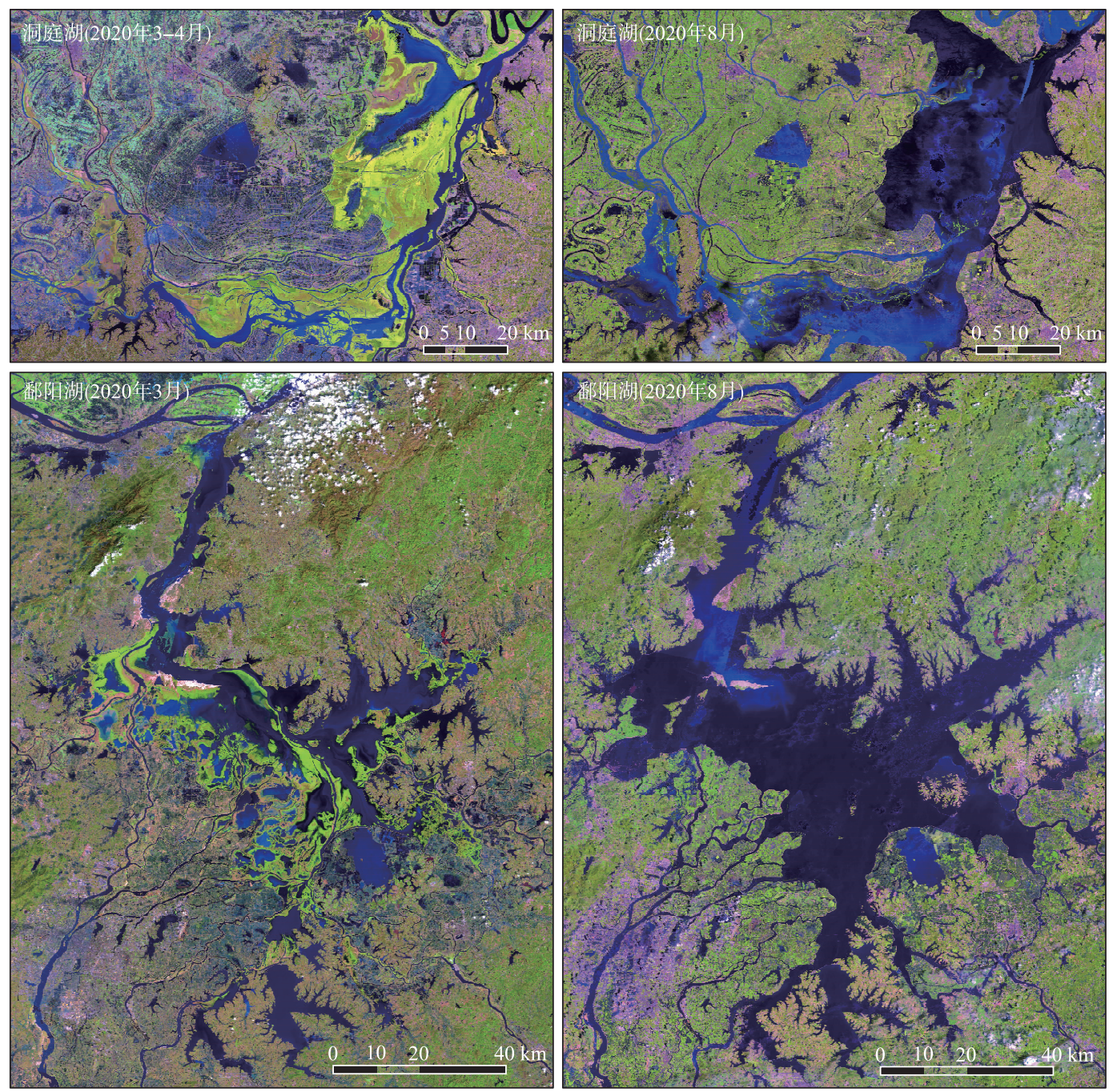

图 3 Landsat 记录的洞庭湖和鄱阳湖洪水变化(最小云量合成影像)

Fig.3 Flood changes in Lake Dongting and Lake Poyang recorded by Landsat ( composite image with lowest cloud cover)

\section{4 水文过程的生态环境效应}

干湿交替的水文过程形成湖泊湿地独特的植物和动物群系. 水文过程可直接、显著改变湿地诸如营养 物质和氧的可获取性、土壤盐渍度、 $\mathrm{pH}$ 和沉积物特性等物理化学条件, 进而影响水质和动植物的群系结 构 ${ }^{[13-114]}$. 同时, 湖泊湿地的植物、动物和水质格局反映了物理化学 (外力) 和生物 (内力) 两种力量之间复 杂、动态的相互作用.

\section{1 水文过程对植物的影响}

植物作为湿地生态系统最重要的组成部分之一,在为水生动物提供食物和栖息地、净化水质、储存碳等 方面发挥着重要作用 ${ }^{[115]}$. 湿地植物变化被认为是指示水环境安全性和可持续性跃迁的关键生态 指标 ${ }^{[116-117]}$. 


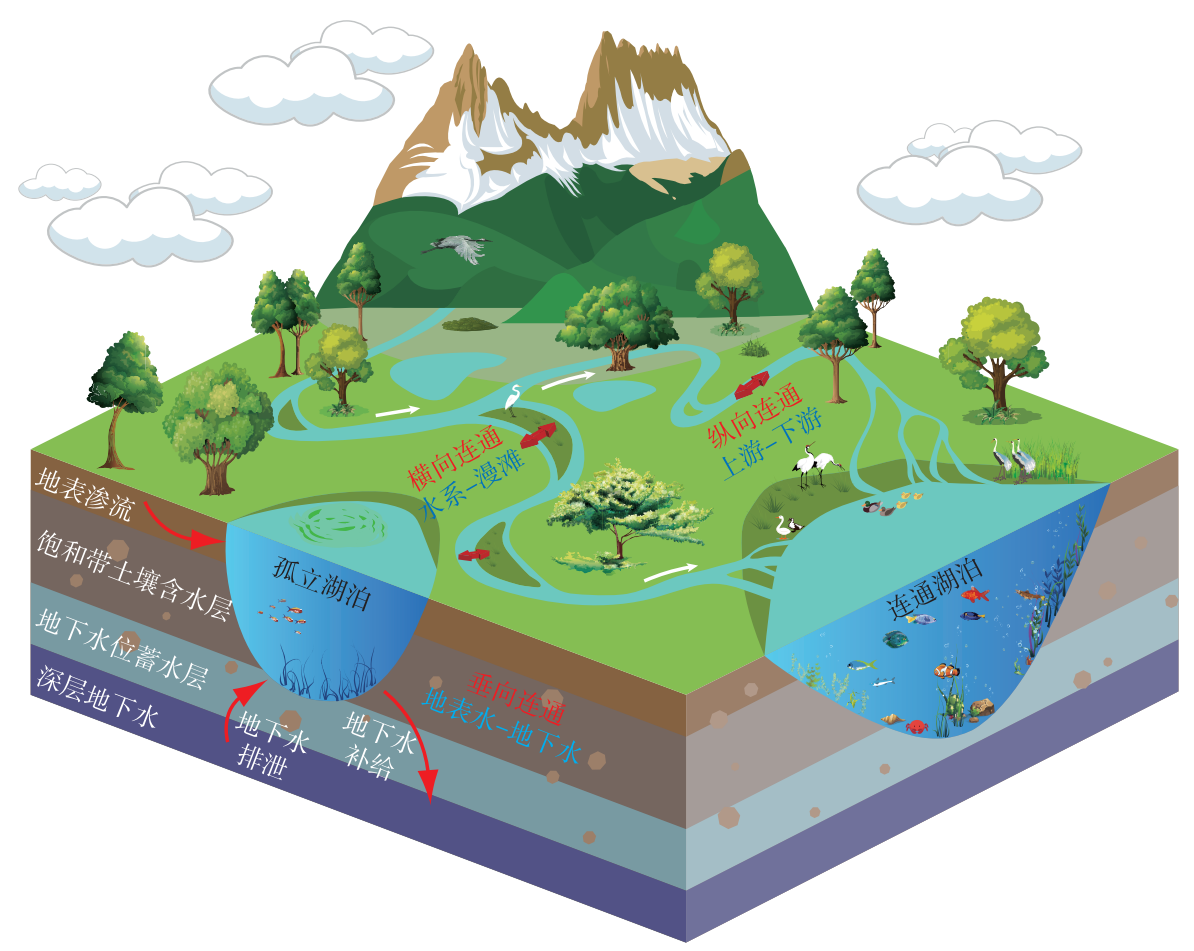

图 4 不同空间维度的水文连通示意图

Fig.4 Schematic diagram of hydrological connectivity in different spatial dimensions

地表水文过程主导了湿地植物的基本生态过程和生态格局, 是湿地植物生态系统演替的主要驱动力 (表 3). 水位直接影响种子萌发、植物存活、生长和繁殖 ${ }^{[118-119]}$, 并通过土壤养分的有效性或种间竞争间接影 响物种组成 ${ }^{[120-121]}$. 例如, 水位下降引起土壤盐分增加, 并且缺水会影响湖滨带植物物种组成, 最终导致某些 植物群落的面积减少甚至消失 ${ }^{[122]}$. 此外, 水文节律改变会导致湿地植物种群结构的变化. 例如, 水位变化幅 度升高会导致建群种的优势度降低 ${ }^{[123]}$.

表 3 湿地植物对地表水文过程的生态响应

Tab.3 Ecological response of wetland plants to surface hydrological process

\begin{tabular}{|c|c|c|c|}
\hline 指标 & 水位变动特征 & 湿生植被的生态响应 & 来源 \\
\hline \multirow[t]{2}{*}{ 持续时间 } & 长期裸露 & 减少植被覆盖度和多样性 & 文献 [124-126] \\
\hline & 长期淹水 & 植被生长率下降、形态改变、死亡率增加, 群落演替 & \\
\hline \multirow[t]{2}{*}{ 淹没深度 } & 高水位 & 湿生植被形态改变,萎缩或死亡 & 文献 [127-129] \\
\hline & 低水位 & 外来物种人侵,群落演替 & \\
\hline 变化率 & 过快 & 湖滨带植被受到冲刷,幼苗难以存活 & 文献 [130] \\
\hline \multirow[t]{2}{*}{ 幅度、频率 } & 变化幅度过大 & 对湿生植被湖岸以及底质的冲刷加剧 & 文献[131-132] \\
\hline & 水文过程过于稳定 & 外来物种人侵,物种多样性降低 & \\
\hline 时机 & 季节性水位峰值次数减少 & 植被发育和生长率减小, 外来物种人侵, 湖滨带萎缩 & 文献 [133] \\
\hline
\end{tabular}

除此之外, 地下水位也是决定植物生长和繁殖的一个关键因素 ${ }^{[134-135]}$. 近几届国际湿地会议 (IWC) 和国 际水文地质大会 $(\mathrm{IAH})$ 分别设置了 “湿地与地下水流” “地下水与湿地的相互影响” 以及 “生态系统中的地 下水作用” 等专题, 在全世界引起关于湿地一地下水交互作用的多学科交叉研究与探讨 ${ }^{[114]}$. 地下水位是地 下水与湿地生态系统之间相互作用的关键性指标 ${ }^{[136]}$. 一方面, 地下水位的微弱变化可能导致生态系统内部 
生物、物理乃至化学过程发生根本变化 ${ }^{[137-138]}$, 造成物种组成以及种群结构改变. 另一方面, 植物生态系统本 身具有一定的自我适应和调节能力, 即不同生活型的植物通过调整物质代谢、能量转化和生长发育适应改 变后的地下水位 ${ }^{[139]}$. 植物对地下水位波动的响应存在两种可能:一种是线性比例响应, 另一种是临界突变 响应 ${ }^{[140]}$. 在现实的植物演替过程中线性响应极为罕见,绝大部分表现为临界突变,即非线性响应: 通常植物 退化对地下水位下降的响应具有一定的滞后期; 这种迟滞效应同样存在于地下水位抬升后植物的恢复过程 中 $^{[30]}$. 当前, “哪些湿地植物依赖地下水?”、“植物蒸腾耗水在什么时段以及多少是来自地下水?”、“引起植 物功能发生正向和逆向改变的地下水位阈值分别是多少?”等问题仍待解答.

\section{2 水文过程对动物的影响}

湖泊湿地特有的水文过程为水鸟、鱼类和无脊椎动物, 特别是其中濒临灭绝的物种提供了理想的栖息 场所. 水文过程变化将显著改变湿地的物质流、能量流和信息流,进而引发不同的动物行为, 比如候鸟迁徙、 鱼类洄游以及无脊椎动物的繁殖和迁徙等. 其中, 水鸟对水文过程变化非常敏感, 其多样性水平常被用来衡 量湖泊湿地生态系统的健康状况 ${ }^{[141]}$.

湖泊湿地提供的浅水、沼泽、滩涂和稀疏草滩是水鸟的天然栖息地和受食场所 ${ }^{[142]}$. 每年春季,太平洋 $70 \%$ (超过 200 万只) 的迁徙水鸟经过俄勒冈南部一加利福尼亚东北部的湖泊湿地 ${ }^{[143]}$, 迁徙高峰期约有 150 万只涉禽在大盐湖停歇, 10.2 万只在莫诺湖, 8.3 万只在阿伯特湖. 水鸟在迁徙途中需要一系列的停歇地补 充食物并积蓄能量, 如果缺失这些湖泊湿地作为栖息地, 就可能导致水鸟向南迁徙失败 ${ }^{[144-145]}$. 鄱阳湖湖泊 水位季节性变化强, 水情特征复杂, 生物多样性丰富, 平均每年有 34 万多只候鸟在此越冬,包括世界上约 $99 \%$ 的白鹤 (Grus leucogeranus) 及超过 80\% 的东方白鹳 (Ciconia boyciana $)^{[146]}$.

在气候变化和快速城市化过程中, 湖泊湿地景观由简单、均匀、连续的整体演变为复杂、异质、间断的斑 块. 鸟类自然栖息地的破碎化越来越严重,可用栖息地和食物资源大量减少,导致种群数量减少,生物多样 性降低 ${ }^{[147-148]}$. 从地中海地区盐田的消失到北美大草原坑洞地区和莫哈韦沙漠湿地的退化, 在气候变化的影 响下大规模的迁徙水鸟 (如水禽、滨鸟、涉禽) 和其他鸟类物种的种群数量正在显著下降 ${ }^{[149-150]}$. 通过研究北 美太平洋航道过去 100 年的水资源利用率和气候变化趋势, 发现农业灌溉和不断增加的蒸发导致水鸟迁徙 路线上融雪流域 $27 \%$ 的湖泊、 $47 \%$ 的湿地和季风流域 $13 \%$ 的湖泊地表水减少,水鸟物种组成发生显著变 化 ${ }^{[151-152]}$. 长江上游的三峡工程运行改变了鄱阳湖洪泛湿地的水文过程, 尤其是浅水面积和水文连通性, 对 越冬水鸟栖息、受食产生直接和间接影响 ${ }^{[153]}$. 研究证实: 群体水平上,天鹅、鹅和鸭的丰度与丰水期月平均 水位显著相关; 涉禽数量与丰水期平均水位和高水位持续时间显著相关 ${ }^{[154]}$. 此外, 上文提到的湿地水文过 程变化导致三江平原水禽数量减少了 $90 \%$ 以上 ${ }^{[155]}$; 松嫩平原湿地鸟类数量由 1983 年的 137 只 $/ \mathrm{km}^{2}$ 减少至 1995 年的 105 只 $/ \mathrm{km}^{2[156]}$ 等.

相反, 湖泊湿地水文条件的改善及合理的水资源利用则有利于水鸟种群数量的增加和物种多样性的恢 复. 例如, 美国自然资源部和 Ducks 无限公司修复了爱荷华州的 38 个浅水湖, 修复后的浅水湖 ( 58 万只,78 种) 比未修复的浅水湖 (13 万只, 70 种) 发现的水鸟数量和种类更多. 修复结果显示, 水位变化对涉水鸭和滨 鸟种群数量有负面影响,对潜水鸭和水鸟物种多样性有正面影响; 水位恢复时长对鹅/天鹅和隐匿沼泽鸟类 物种多样性有正面影响; 湿地总面积对各类群数量和多样性均有正面影响 ${ }^{[157]}$. 此外, 受河湖连通工程影响, 莫莫格湿地过境白鹤数量由原来的 500 多只增加到 3800 多只, 占全球白鹤数量的 $95 \%{ }^{[97]}$. 对云南大理洱海 的候鸟种群动态的持续观测发现, 水位下降后钻水鸭和潜水类的种群数量和物种多样性都有所增加 ${ }^{[158]}$.

\section{3 水文过程对水质的影响}

湿地水文过程对于水质的影响同时表现为湿地的源和汇的功能. 一方面, 湿地是下游水域溶解性有机 物、营养物和污染物等的重要来源. 例如, 磷和硝态氮等受 “蓄积一溢出” 效应或近地表电势差驱动由底泥释 放至上层水体,并随着地表水或浅层地下水转移到下游水域,起到化学源的功能 ${ }^{[103,159]}$. 对大型浅水湖泊而 言, 风浪发育充分, 底泥再悬浮频繁, 磷的内源供给通量大、速度快、效率高 ${ }^{[160]}$. 例如, 基于静态释放培养法 估算的太湖内源磷负荷可达 $899 \mathrm{t} / \mathrm{a}^{[161]}$, 而基于动态释放的通量则更高 ${ }^{[162-163]}$. 此外, 湿地植物在完成一个 生命周期后调落物会落人水中, 分解并释放有机物和氮进人水体, 进而增加水体中氮浓度 ${ }^{[164]}$. 研究发现, 湿 地植物的秋季 1 次收获对土壤中氮的去除量最大 $\left(81.62 \mathrm{~g} / \mathrm{m}^{2}\right)$, 说明土壤微生物的硝化和反硝化作用对土 
壤脱氮的贡献最显著 ${ }^{[165]}$.

另一方面, 湿地通过储水稀释、沉淀和置换作用对有机物、营养物和污染物等进行截留, 使得氮、磷及一 些重金属元素在植物一土壤系统中周转, 最终达到富集的效果, 从而发挥化学汇的功能 ${ }^{[6,166]}$. 例如, 湖泊是 氮最重要的汇库之一, 氮可以被反硝化、固定或储存在沉积物中 ${ }^{[167]}$. Harrison 等估计全球湖泊每年可去除约 $13 \mathrm{Tg}$ 的氮, 占内陆水域氮输人量的 $20 \%{ }^{[168]}$. 沉积物通过反硝化将硝酸盐 $\left(\mathrm{HNO}_{3}\right)$ 转化成氧化亚氮 $\left(\mathrm{N}_{2} \mathrm{O}\right)$ 和 氮气 $\left(N_{2}\right)$ 实现对氮的永久性去除, 是湖泊生态系统中主要的氮去除途径 ${ }^{[169]}$. 沉积物也是磷的一个即时 “储

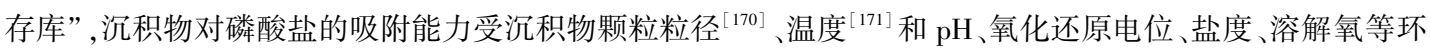
境因子影响 ${ }^{[172-174]}$. 此外, 湿地植物根系发达, 生长速度快, 生物量大, 在生态系统中对金属的吸收、转运和生 物地球化学循环起着至关重要的作用 ${ }^{[175]}$. 研究表明,一些湿地植物, 如芦苇 (Phragmites australis) ${ }^{[175]}$ 、香蒲 (Typha latifolia Linn.) ${ }^{[176]}$ 以及莎草 (Cyperus articulatus L) 表现出很高的金属积累能力 ${ }^{[177]}$.

湖泊湿地地表水的横向、纵向、垂向运移随时间和空间变化,水文过程对水质影的源、汇和滞后效应往 往同时发生, 进而抵消它们作为下游水域物质和能量来源的作用. 如何提高湖泊湿地的固碳作用, 探索碳达 峰、碳中和的实现路径是未来湖泊湿地水文生态研究的重要方向.

\section{5 展望}

作为一种具有全球意义的自然资源, 湖泊湿地生态系统在过去一个世纪发生了重大改变, 由此带来的 生态环境压力和社会经济问题受到广大学者的广泛关注. 湖泊湿地水文过程已成为当前水资源管理、水文 地球化学和生态水文学等多个领域的研究热点和前沿. 在已有研究建立的科学理论和开创性认识的基础 上,未来在以下 5 个方面有待探索和创新: 湖泊湿地多要素综合观测体系、气候变化与人类活动协同作用机 制、水文连通多维度转化机理及其生态效应、地下水驱动下的植物非线性演变规律和基于关键水文要素的 水鸟栖息地质量评价.

1) 湿地多要素综合观测体系. 在湿地关键水文要素监测方面, 主流的多源遥感数据融合方法建立在预 测期内没有土地覆盖变化或只存在线性变化的假设基础上, 而这一假设并不适用于快速变化的湿地水文要 素监测. 此外, 融合过程需要的成对无云影像, 在受多云覆盖影响的湿润区很难得到满足. 当前, 迫切需要突 破上述瓶颈改进多源数据时空融合技术. 此外, 随着遥感产品日趋丰富以及水文模型的逐渐成熟, 遥感科学 与水文学相结合为湿地水文要素监测开拓了更为广阔的前景. 水文/水动力模型通过结合遥感技术提供的 地形、土地利用和植被等下垫面信息以及降水、蒸散发等气象参数, 实现关键水文要素的长期、动态和连续 模拟和预测是未来湖泊湿地生态水文过程研究的重要方向.

2)气候变化与人类活动协同作用机制. 受气候变化和人类用水增加,特别是灌溉耗水影响, 世界各地的 湖泊湿地面临减少和退化风险. 政府通过教育和激励的手段调整农业用水方式, 分担基础灌溉设施的成本 支持生产者, 从而获得在节约用水和维护湿地生境方面的生态补偿. 与此同时, 灌溉效率的提升会导致农业 生产者种植更多的耗水作物和扩大种植面积. 因而需要不断地将新的节水措施重新应用于生态系统服务, 针对湖泊湿地生态水文系统与农业发展、水资源开发利用等社会经济系统相互作用的双向机制, 制定湖泊 湿地管理的政策制度和规划方案, 提升湖泊湿地生态服务功能.

3) 水文连通多维度转化机理及其生态效应. 水文连通性伴随着水循环过程的发展表现出动态性、多维 性、系统性、阈值性和异质性等主要特征. 同水文过程相比, 水文连通性更加侧重于从系统角度来识别水流 的空间联系与多维度转化. 尽管相关研究在纵向和横向地表水文连通性方面取得较多进展, 但受地表一地下 水交互作用的复杂性以及土壤水变化的时间动态性和空间异质性影响, 垂向水文连通性研究仍有不足. 如 何探明洪泛系统多维度水文连通时空转化的协同性、连续性和临界条件是维护湖泊湿地结构完整, 提升生 态系统服务功能亟待解决的一个关键科学问题.

4) 地下水驱动下的植物非线性演变规律. 地下水位是地下水与湿地生态系统之间相互作用的关键性指 标. 然而, 由于湿润区地表水资源相对丰富, 地下水对湿地植物的作用和贡献往往被忽视. 地下水位波动的 方式、强度和频率无疑会影响植物退化/恢复的非线性过程, 改变湿地植物演替的方向、速度、趋势或终结类 型, 甚至带来不可挽回的退化结果. 如何定量刻画植物对地下水变化的响应仍面临挑战. 亟需从生态水文学 
的角度研究洪泛湿地不同生活型植物种群退化/恢复过程对地下水位波动的响应差异及其演变的非线性动 力学机制, 为湖泊水位调控和退化湿地的恢复提供科学依据.

5) 基于关键水文要素的水鸟栖息地质量评价. 湖泊湿地资源的空间位置及其相对于个体物种迁徙时间 的可用性是评估水鸟栖息地质量的必要条件. 无论是由于湿地丧失、可利用时间的改变,还是不合适的盐度 或水深,都可能导致栖息地适宜度降低或候鸟迁徙失败. 因此,需要更精细的栖息地质量评估来充分了解特 定物种的弹性力和恢复力. 当前, 对候鸟迁徙路线的可持续性主要围绕以保护湿地这一土地利用类型为目 标的政策调整,而忽略了对决定湖泊湿地生态功能的关键水文过程的影响评价,如洪水发生的时机、范围、 强度、频率、历时以及涨退水速率等. 基于湖泊湿地关键水文过程, 综合考虑水鸟受食场所的可用性和栖息 场所的安全性,才能为水鸟提供最佳的生境条件.

\section{6 参考文献}

[ 1 ] Lv XG ed. Wetland ecosystem study in China. Shijiazhuang: Hebei Science and Technology Publishing House, 2008. [吕 宪国. 中国湿地与湿地研究. 石家庄: 河北科学技术出版社, 2008.]

[ 2 ] Woolway RI, Kraemer BM, Lenters JD et al. Global lake responses to climate change. Nature Reviews Earth \& Environment, 2020, 1(8) : 388-403. DOI: 10.1038/s43017-020-0067-5.

[ 3 ] Lehner B, Döll P. Development and validation of a global database of lakes, reservoirs and wetlands. Journal of Hydrolo$g y, 2004,296(1 / 2 / 3 / 4)$ : 1-22. DOI : 10.1016/j.jhydrol.2004.03.028.

[ 4 ] Xu XB, Yang GS, Jiang B. Progress in lake-wetland ecosystem services. Acta Ecologica Sinica, 2018, 38(20): 7149 7158. [徐昔保, 杨桂山，江波. 湖泊湿地生态系统服务研究进展. 生态学报, 2018, 38(20): 7149-7158.]

[ 5 ] Covino T. Hydrologic connectivity as a framework for understanding biogeochemical flux through watersheds and along fluvial networks. Geomorphology, 2017, 277: 133-144. DOI: 10.1016/j.geomorph.2016.09.030.

[ 6 ] Li YL, Zhang Q, Cai YJ et al. Hydrodynamic investigation of surface hydrological connectivity and its effects on the water quality of seasonal lakes: Insights from a complex floodplain setting (Poyang Lake, China). Science of the Total Environment, 2019, 660: 245-259. DOI : 10.1016/j.scitotenv.2019.01.015.

[ 7 ] Bai JH, Guan YN, Liu PP et al. Assessing the safe operating space of aquatic macrophyte biomass to control the terrestrialization of a grass-type shallow lake in China. Journal of Environmental Management, 2020, 266: 110479. DOI: 10.1016/ j.jenvman.2020.110479.

[ 8 ] Sharp JL, Sojda RS, Greenwood M et al. Statistical classification of vegetation and water depths in montane wetlands. Ecohydrology, 2013, 6(2) : 173-181. DOI: 10.1002/eco.1252.

[ 9 ] Li X, Cui BS, Yang QC et al. Impacts of water level fluctuations on detritus accumulation in Lake Baiyangdian, China. Ecohydrology, 2016, 9(1) : 52-67. DOI: 10.1002/eco.1610.

[10] Wang JD, Song CQ, Reager JT et al. Recent global decline in endorheic basin water storages. Nature Geoscience, 2018,11 (12) : 926-932. DOI : 10.1038/s41561-018-0265-7.

[11] Wada Y, van Beek LPH, Wanders N et al. Human water consumption intensifies hydrological drought worldwide. Environmental Research Letters, 2013, 8(3) : 034036. DOI: 10.1088/1748-9326/8/3/034036.

[12] Wurtsbaugh WA, Miller C, Null SE et al. Decline of the world's saline lakes. Nature Geoscience, 2017, 10(11): 816821. DOI: $10.1038 /$ ngeo3052.

[13] Zimmer KD, Hobbs WO, Domine LM et al. Uniform carbon fluxes in shallow lakes in alternative stable states. Limnology and Oceanography, 2016, 61(1) : 330-340. DOI: 10.1002/lno.10215.

[14] Hall RK, Lin J, Schumacher BA et al. Ecological risk based assessment used to restore riparian physical functions to a fresh water Creek. Journal of Environmental Management, 2018, 221: 63-75. DOI: 10.1016/j.jenvman.2018.03.117.

[15] Davidson NC. How much wetland has the world lost? Long-term and recent trends in global wetland area. Marine and Freshwater Research, 2014, 65(10) : 934. DOI: 10.1071/mf14173.

[16] Niu ZG, Zhang HY, Wang XW et al. Mapping wetland changes in China between 1978 and 2008. Chinese Science Bulletin, 2012, 57(22) : 2813-2823. DOI: 10.1007/s11434-012-5093-3.

[17] Silvertown J, Dodd ME, Gowing DJG et al. Hydrologically defined niches reveal a basis for species richness in plant communities. Nature, 1999, 400(6739) : 61-63. DOI: 10.1038/21877. 
[18] Tan ZQ, Jiang JH. Spatial-temporal dynamics of wetland vegetation related to water level fluctuations in Poyang Lake, China. Water, 2016, 8(9) : 397. DOI: 10.3390/w8090397.

[19] Tan ZQ, Li YL, Xu XL et al. Mapping inundation dynamics in a heterogeneous floodplain: Insights from integrating observations and modeling approach. Journal of Hydrology, 2019, 572 : 148-159. DOI : 10.1016/j.jhydrol.2019.02.039.

[20] Chen B, Chen LF, Huang B et al. Dynamic monitoring of the Poyang Lake wetland by integrating Landsat and MODIS observations. ISPRS Journal of Photogrammetry and Remote Sensing, 2018, 139: 75-87. DOI: 10.1016/j. isprsjprs. 2018. 02.021 .

[21] Liu D, Cao CX, Chen W et al. Monitoring and predicting the degradation of a semi-arid wetland due to climate change and water abstraction in the Ordos Larus relictus National Nature Reserve, China. Geomatics, Natural Hazards and Risk, 2017, 8(2) : 367-383. DOI: 10.1080/19475705.2016.1220024.

[22] Shaw JB, Mohrig D. The importance of erosion in distributary channel network growth, Wax Lake Delta, Louisiana, USA. Geology, 2014, 42(1) : 31-34. DOI: 10.1130/g34751.1.

[23] Deng XJ, Xu YP, Han LF et al. Spatial-temporal changes in the longitudinal functional connectivity of river systems in the Taihu Plain, China. Journal of Hydrology, 2018, 566: 846-859. DOI: 10.1016/j.jhydrol.2018.09.060.

[24] Mansell RS, Bloom SA, Sun G. A model for wetland hydrology: Description and validation. Soil Science, 2000, 165(5): 384-397. DOI: 10.1097/00010694-200005000-00002.

[25] Restrepo JI, Montoya AM, Obeysekera J. A wetland simulation module for the MODFLOW ground water model. Groundwater, 1998, 36(5) : 764-770. DOI: 10.1111/j.1745-6584.1998.tb02193.x.

[26] Skaggs RW. Field evaluation of a water management simulation model. Transactions of the ASAE, 1982, 25(3): 666-674. DOI : $10.13031 / 2013.33592$.

[27] Singh VP ed. Computer models of watershed hydrology. Lausanne: Water Resources Publications, 1995.

[28] Simunek J, Sejna M, Van Genuchten MT et al. HYDRUS-1D. Simulating the one-dimensional movement of water, heat, and multiple solutes in variably-saturated media, version 2, 1998.

[29] Yan DH ed. Applied ecohydrology. Beijing: Science Press, 2014. [严登华. 应用生态水文学. 北京: 科学出版 社, 2014.]

[30] Chui TFM, Low SY, Liong SY. An ecohydrological model for studying groundwater-vegetation interactions in wetlands. Journal of Hydrology, 2011, 409(1/2) : 291-304. DOI: 10.1016/j.jhydrol.2011.08.039.

[31] Park E, Latrubesse EM. The hydro-geomorphologic complexity of the lower Amazon River floodplain and hydrological connectivity assessed by remote sensing and field control. Remote Sensing of Environment, 2017, 198: 321-332. DOI: 10. 1016/j.rse.2017.06.021.

[32] Li Y, Gao HL, Jasinski MF et al. Deriving high-resolution reservoir bathymetry from ICESat-2 prototype photon-counting lidar and landsat imagery. IEEE Transactions on Geoscience and Remote Sensing, 2019, 57(10) : 7883-7893. DOI: 10. 1109/TGRS.2019.2917012.

[33] Jiang LG, Schneider R, Andersen O et al. CryoSat-2 altimetry applications over rivers and lakes. Water, 2017, 9(3): 211. DOI: $10.3390 / \mathrm{w} 9030211$.

[34] Hwang C, Cheng YS, Yang WH et al. Lake level changes in the Tibetan Plateau from Cryosat-2, SARAL, ICESat, and Jason-2 altimeters. Terrestrial, Atmospheric and Oceanic Sciences, 2019, 30 (1) : 33-50. DOI : 10.3319/tao.2018.07. 09.01 .

[35] Shu S, Liu HX, Beck RA et al. Analysis of Sentinel-3 SAR altimetry waveform retracking algorithms for deriving temporally consistent water levels over ice-covered lakes. Remote Sensing of Environment, 2020, 239: 111643. DOI: 10.1016/j. rse.2020.111643.

[36] Baup F, Frappart F, Maubant J. Combining high-resolution satellite images and altimetry to estimate the volume of small lakes. Hydrology and Earth System Sciences, 2014, 18(5) : 2007-2020. DOI: 10.5194/hess-18-2007-2014.

[37] Alsdorf DE, Melack JM, Dunne T et al. Interferometric radar measurements of water level changes on the Amazon flood plain. Nature, 2000, 404(6774) : 174-177. DOI : 10.1038/35004560.

[38] Crétaux JF, Bergé-Nguyen M, Calmant S et al. Calibration of Envisat radar altimeter over Lake Issykkul. Advances in Space Research, 2013, 51(8) : 1523-1541. DOI: 10.1016/j.asr.2012.06.039.

[39] Babaeian E, Sadeghi M, Jones SB et al. Ground, proximal, and satellite remote sensing of soil moisture. Reviews of Geo- 
physics, 2019, 57(2) : 530-616. DOI: 10.1029/2018RG000618.

[40] Pantaleoni E, Wynne RH, Galbraith JM et al. Mapping wetlands using ASTER data: A comparison between classification trees and logistic regression. International Journal of Remote Sensing, 2009, 30 ( 13 ): 3423-3440. DOI: 10. 1080/01431160802562214.

[41] Davranche A, Lefebvre G, Poulin B. Wetland monitoring using classification trees and SPOT-5 seasonal time series. Remote Sensing of Environment, 2010, 114(3) : 552-562. DOI: 10.1016/j.rse.2009.10.009.

[ 42] Pekel JF, Cottam A, Gorelick N et al. High-resolution mapping of global surface water and its long-term changes. Nature, 2016, 540(7633) : 418-422. DOI: 10.1038/nature20584.

[43] Zhao G, Gao HL. Automatic correction of contaminated images for assessment of reservoir surface area dynamics. Geophysical Research Letters, 2018, 45(12) : 6092-6099. DOI: 10.1029/2018GL078343.

[44] Yao FF, Wang JD, Wang C et al. Constructing long-term high-frequency time series of global lake and reservoir areas using Landsat imagery. Remote Sensing of Environment, 2019, 232: 111210. DOI: 10.1016/j.rse.2019.111210.

[45] Feng L, Hu C, Chen X et al. Assessment of inundation changes of Poyang Lake using MODIS observations between 2000 and 2010. Remote Sensing of Environment, 2012, 121: 80-92.

[46] Lu SL, Jia L, Zhang L et al. Lake water surface mapping in the Tibetan Plateau using the MODIS MOD09Q1 product. Remote Sensing Letters, 2017, 8(3) : 224-233. DOI: 10.1080/2150704X.2016.1260178.

[47] Wang JD, Sheng YW, Tong TSD. Monitoring decadal lake dynamics across the Yangtze Basin downstream of Three Gorges Dam. Remote Sensing of Environment, 2014, 152: 251-269. DOI: 10.1016/j.rse.2014.06.004.

[48] Bryant RG, Rainey MP. Investigation of flood inundation on playas within the Zone of Chotts, using a time-series of AVHRR. Remote Sensing of Environment, 2002, 82(2/3) : 360-375. DOI: 10.1016/S0034-4257(02) 00053-6.

[49] Li SM, Sun DL, Goldberg M et al. Derivation of 30-m-resolution water maps from TERRA/MODIS and SRTM. Remote Sensing of Environment, 2013, 134: 417-430. DOI: 10.1016/j.rse.2013.03.015.

[50] Gao F, Hilker T, Zhu XL et al. Fusing landsat and MODIS data for vegetation monitoring. IEEE Geoscience and Remote Sensing Magazine, 2015, 3(3) : 47-60. DOI: 10.1109/MGRS.2015.2434351.

[51] Wu MQ, Wu CY, Huang WJ et al. An improved high spatial and temporal data fusion approach for combining Landsat and MODIS data to generate daily synthetic Landsat imagery. Information Fusion, 2016, 31: 14-25. DOI: 10.1016/j.inffus. 2015.12.005.

[52] Chen B, Huang B, Xu B. A hierarchical spatiotemporal adaptive fusion model using one image pair. International Journal of Digital Earth, 2017, 10(6) : 639-655. DOI : 10.1080/17538947.2016.1235621.

[53] Tan Z, Melack J, Li Y et al. Estimation of water volume in ungauged, dynamic floodplain lakes. Environmental Research Letters, 2020, 15(5) : 054021. DOI: 10.1088/1748-9326/ab82cb.

[54] Gao F, Masek J, Schwaller M et al. On the blending of the Landsat and MODIS surface reflectance: Predicting daily Landsat surface reflectance. IEEE Transactions on Geoscience and Remote Sensing, 2006, 44(8) : 2207-2218. DOI: 10.1109/ TGRS.2006.872081.

[55] Roy DP, Ju JC, Lewis P et al. Multi-temporal MODIS-Landsat data fusion for relative radiometric normalization, gap filling, and prediction of Landsat data. Remote Sensing of Environment, 2008, 112 (6) : 3112-3130. DOI: 10.1016/j.rse. 2008.03.009.

[56] Hilker T, Wulder MA, Coops NC et al. A new data fusion model for high spatial- and temporal-resolution mapping of forest disturbance based on Landsat and MODIS. Remote Sensing of Environment, 2009, 113(8) : 1613-1627. DOI: 10.1016/j. rse.2009.03.007.

[57] Zhu XL, Chen J, Gao F et al. An enhanced spatial and temporal adaptive reflectance fusion model for complex heterogeneous regions. Remote Sensing of Environment, 2010, 114(11) : 2610-2623. DOI : 10.1016/j.rse.2010.05.032.

[58] Wu M, Niu Z, Wang C et al. Use of MODIS and Landsat time series data to generate high-resolution temporal synthetic Landsat data using a spatial and temporal reflectance fusion model. Journal of Applied Remote Sensing, 2012, 6 (1) : 063507 .

[59] Wu MQ, Huang WJ, Niu Z et al. Validation of synthetic daily Landsat NDVI time series data generated by the improved spatial and temporal data fusion approach. Information Fusion, 2018, 40: 34-44. DOI : 10.1016/j.inffus.2017.06.005.

[60] Busetto L, Meroni M, Colombo R. Combining medium and coarse spatial resolution satellite data to improve the estimation 
of sub-pixel NDVI time series. Remote Sensing of Environment, 2008, 112(1) : 118-131. DOI: 10. 1016/j. rse. 2007. 04.004 .

[61] Meng JH, Du X, Wu BF. Generation of high spatial and temporal resolution NDVI and its application in crop biomass estimation. International Journal of Digital Earth, 2013, 6(3) : 203-218. DOI : 10.1080/17538947.2011.623189.

[62] Jin ZY, Xu B. A novel compound smoother-RMMEH to reconstruct MODIS NDVI time series. IEEE Geoscience and Remote Sensing Letters, 2013, 10(4) : 942-946. DOI: 10.1109/LGRS.2013.2253760.

[63] Rao YH, Zhu XL, Chen J et al. An improved method for producing high spatial-resolution NDVI time series datasets with multi-temporal MODIS NDVI data and landsat TM/ETM+ images. Remote Sensing, 2015, 7(6) : 7865-7891. DOI: 10. 3390/rs70607865.

[64] Dong LQ, Zhang GX. Review of the impacts of climate change on wetland ecohydrology. Advances in Water Science, 2011, 22(3) : 429-436. [ 董李勤, 章光新. 全球气候变化对湿地生态水文的影响研究综述. 水科学进展, 2011, 22(3): 429-436. ]

[65] Woolway RI, Merchant CJ. Intralake heterogeneity of thermal responses to climate change: A study of large Northern Hemisphere lakes. Journal of Geophysical Research: Atmospheres, 2018, 123(6) : 3087-3098. DOI : 10.1002/2017JD027661.

[66] Lawler JJ. Climate change adaptation strategies for resource management and conservation planning. Annals of the New York Academy of Sciences, 2009, 1162: 79-98. DOI : 10.1111/j.1749-6632.2009.04147.x.

[67] Song CQ, Sheng YW, Zhan SG et al. Impact of amplified evaporation due to lake expansion on the water budget across the inner Tibetan Plateau. International Journal of Climatology, 2020, 40(4) : 2091-2105. DOI: 10.1002/joc.6320.

[68] Wang GD, Wang M, Lu XG et al. Duration of farming is an indicator of natural restoration potential of sedge meadows. Scientific Reports, 2017, 7 : 10692. DOI: 10.1038/s41598-017-11429-0.

[69] Sharma S, Blagrave K, Magnuson JJ et al. Widespread loss of lake ice around the Northern Hemisphere in a warming world. Nature Climate Change, 2019, 9(3) : 227-231. DOI: 10.1038/s41558-018-0393-5.

[ 70] Song CC. Influence of global climate change on wetlands. Wetland Science, 2003, 1(2) : 122-127. [宋长春. 湿地生态系 统对气候变化的响应. 湿地科学, 2003, 1(2): 122-127.]

[71] Werner BA, Johnson WC, Guntenspergen GR. Evidence for 20th century climate warming and wetland drying in the North American Prairie Pothole Region. Ecology and Evolution, 2013: 3471-3482. DOI: 10.1002/ece3.731.

[72] Aydin F, Erlat E, Türkeş M. Impact of climate variability on the surface of Lake Tuz (Turkey), 1985-2016. Regional Environmental Change, 2020, 20(2) : 1-14. DOI: 10.1007/s10113-020-01656-z.

[73] Larson DL. Effects of climate on numbers of northern prairie wetlands. Climatic Change, 1995, 30(2) : 169-180. DOI: 10.1007/BF01091840.

[74] Schoning K, Charman DJ, Wastegoard S. Reconstructed water tables from two ombrotrophic mires in eastern central Sweden compared with instrumental meteorological data. The Holocene, 2005, 15 ( 1 ): 111-118. DOI: 10. 1191/0959683605hl772rp.

[75] Kamocki A, Banaszuk P. Modelling hydrological changes of fluviogenous wetland: a landscape-scale GIS approach. Publications of the Institute of Geophysics Polish Academy of Sciences, 2008, 405: 18-26.

[76] Chen KL ed. China wetlands encyclopedia. Beijing: Beijing Science and Technology Press, 2009. [陈克林. 中国湿地百 科全书. 北京: 北京科学技术出版社, 2009.]

[77] Li L, Li FX, Zhu XD et al. Quantitative identification of driving force on wetland shrinkage over the source region of the Yellow River. Journal of Natural Resources, 2009, 24(7) : 1246-1255. [李林, 李凤霞, 朱西德等. 黄河源区湿地萎缩 驱动力的定量辨识. 自然资源学报, 2009, 24(7): 1246-1255.]

[78] Wang H, Xu SG, Sun LS. The prediction on reed swamp evapotranspiration in Zhalong wetland, China. Acta Ecologica Sinica, 2006, 26(5) : 1352-1358. [王吴, 许士国, 孙砳石. 扎龙湿地芦苇沼泽蒸散耗水预测. 生态学报, 2006, 26 (5): 1352-1358.]

[79] Yang Y, Yin XN, Yang ZF. Environmental flow management strategies based on the integration of water quantity and quality, a case study of the Baiyangdian Wetland, China. Ecological Engineering, 2016, 96: 150-161. DOI : 10.1016/j.ecoleng.2015.12.018.

[80] Dubrovsky M, Nemesova I, Kalvova J. Uncertainties in climate change scenarios for the Czech Republic. Climate Research, 2005, 29: 139-156. DOI: 10.3354/cr029139. 
[81] Cahynová M, Huth R. Changes of atmospheric circulation in central Europe and their influence on climatic trends in the Czech Republic. Theoretical and Applied Climatology, 2009, 96(1/2) : 57-68. DOI: 10.1007/s00704-008-0097-2.

[82] Coumou D, Rahmstorf S. A decade of weather extremes. Nature Climate Change, 2012, 2(7) : 491-496.

[83] Koutsoyiannis D. Hurst-Kolmogorov dynamics and uncertainty. Journal of the American Water Resources Association, 2011, 47(3) : 481-495. DOI: 10.1111/j.1752-1688.2011.00543.x.

[84] Westra S, Alexander LV, Zwiers FW. Global increasing trends in annual maximum daily precipitation. Journal of Climate, 2013, 26(11) : 3904-3918. DOI: 10.1175/jcli-d-12-00502.1.

[85] Woolway RI, Jennings E, Shatwell T et al. Lake heatwaves under climate change. Nature, 2021, 589(7842) : 402-407. DOI: $10.1038 / \mathrm{s} 41586-020-03119-1$.

[86] CMA Climate Change Centre ed. Blue book on climate change in China (2021). Beijing: Science Press, 2021. [中国气 象局气候变化中心. 中国气候变化蓝皮书(2021). 北京: 科学出版社, 2021.]

[87] Liu CL, Xie GD, Xiao Y. Impact of climatic change on Baiyangdian wetland. Resources and Environment in the Yangtze Basin, 2007, 16(2) : 245-250. [刘春兰, 谢高地, 肖玉. 气候变化对白洋淀湿地的影响. 长江流域资源与环境, $2007, \mathbf{1 6}(2): 245-250$.]

[88] Johnson WC, Millett BV, Gilmanov T et al. Vulnerability of northern prairie wetlands to climate change. BioScience, 2005, 55(10) : 863-872. DOI : 10.1641/0006-3568(2005) 055[0863: VONPWT] 2.0.CO;2.

[89] Wright CK, Wimberly MC. Recent land use change in the Western Corn Belt threatens grasslands and wetlands. PNAS, 2013, 110(10) : 4134-4139. DOI: 10.1073/pnas.1215404110.

[90] Dahl TE. Status and trends of wetlands in the conterminous United States 2004 to 2009. US Department of the Interior, US Fish and Wildlife Service, Fisheries and Habitat Conservation, 2011.

[91] Li WY. Study on marsh wetland ecological carrying capacity and controlling pattern of the sustainable development on Sanjiang Plain [Dissertation]. Harbin: Northeast Agricultural University, 2007. [李伟业. 三江平原沼泽湿地生态承载力 与可持续调控模式研究 [学位论文]. 哈尔滨: 东北农业大学, 2007.]

[92] Zhang Q, Li L, Wang YG et al. Has the Three-Gorges Dam made the Poyang Lake wetlands wetter and drier?. Geophysical Research Letters, 2012, 39(20): L20402. DOI: 10.1029/2012GL053431.

[93] Lai XJ, Shankman D, Huber C et al. Sand mining and increasing Poyang Lake's discharge ability: A reassessment of causes for lake decline in China. Journal of Hydrology, 2014, 519: 1698-1706. DOI: 10.1016/j.jhydrol.2014.09.058.

[94] Min Q, Liu Y, Ma DG. Impact of restoring lake by stopping cultivation on flood control capacity of Poyang Lake. Resources and Environment in the Yangtze Basin, 2006, 15(5) : 574-578. [ 闵骞, 刘影, 马定国. 退田还湖对鄱阳湖洪水调控能 力的影响. 长江流域资源与环境, 2006, 15(5): 574-578.]

[95] Zhuang DC, Ou WX, Ding DS. Evaluation of the lake recovery area eco-economy benefit in Dongting Lake wetland. Journal of Natural Resources, 2003, 18(5) : 536-543. [ 庄大昌, 欧维新, 丁登山. 洞庭湖湿地退田还湖的生态经济效益 研究. 自然资源学报, 2003, 18(5): 536-543.]

[96] Su WC. Main ecological and environmental problems of water-level-fluctuation zone( WLFZ) in Three Gorges reservoir and their controlling measures. Journal of Yangtze River Scientific Research Institute, 2004, 21(2) : 32-34,41. [苏维词. 三峡 库区消落带的生态环境问题及其调控. 长江科学院院报, 2004, 21(2) : 32-34,41.]

[97] Cai BF. Research on the optimization model of ecosystem service value of river-lake connectivity project in Western Jilin Province [Dissertation]. Changchun: Jilin University, 2019. [蔡宝峰. 吉林西部地区河湖连通工程生态系统服务价 值优化模型研究 [学位论文]. 长春: 吉林大学, 2019.]

[98] Kummu M, Tes S, Yin S et al. Water balance analysis for the Tonle Sap Lake-floodplain system. Hydrological Processes, 2014, 28(4) : 1722-1733. DOI: 10.1002/hyp.9718.

[99] Bonnet MP, Barroux G, Martinez JM et al. Floodplain hydrology in an Amazon floodplain lake (Lago Grande de Curuaí). Journal of Hydrology, 2008, 349(1/2) : 18-30. DOI: 10.1016/j.jhydrol.2007.10.055.

[100] Chen MF, Li AQ, Ma Q. Analysis of regulation and storage of Dongting Lake in 2020 flood. Express Water Resources \& Hydropower Information, 2021, 42(1):33-38. [陈莫非, 李安强, 马强. 2020 年洪水洞庭湖调蓄作用分析. 水利水电快 报, 2021, 42(1): 33-38.]

[101] Ma Q, Liu JM, Lu CW. Analysis of effect of resident moved-out polder in the Poyang Lake Area in 2020 and some thoughts on flood control. Express Water Resources \& Hydropower Information, 2021 , 42(1) : 39-42, 72. [马强, 刘佳明, 
卢程伟. 2020 年鄱阳湖区单退圩堤运用效果分析及湖区防洪治理思考. 水利水电快报, 2021, 42(1): 39-42, 72.]

[102] Keys TA, Govenor H, Jones CN et al. Effects of large wood on floodplain connectivity in a headwater Mid-Atlantic stream. Ecological Engineering, 2018, 118: 134-142. DOI: 10.1016/j.ecoleng.2018.05.007.

[103] Beck WJ, Moore PL, Schilling KE et al. Changes in lateral floodplain connectivity accompanying stream channel evolution: Implications for sediment and nutrient budgets. Science of the Total Environment, 2019, 660: 1015-1028. DOI: 10. 1016/j. scitotenv.2019.01.038.

[104] Tan ZQ, Li YL, Zhang Q et al. Assessing effective hydrological connectivity for floodplains with a framework integrating habitat suitability and sediment suspension behavior. Water Research, 2021, 201: 117253. DOI: 10. 1016/j. watres. 2021.117253 .

[105] Li YL, Tan ZQ, Zhang Q et al. Refining the concept of hydrological connectivity for large floodplain systems: Framework and implications for eco-environmental assessments. Water Research, 2021, 195: 117005. DOI: 10. 1016/j. watres. 2021.117005 .

[106] van der Most M, Hudson PF. The influence of floodplain geomorphology and hydrologic connectivity on Alligator gar (Atractosteus spatula) habitat along the embanked floodplain of the Lower Mississippi River. Geomorphology, 2018, 302 : 6275. DOI: 10.1016/j.geomorph.2017.09.032.

[107] Zarfl C, Lumsdon AE, Berlekamp J et al. A global boom in hydropower dam construction. Aquatic Sciences, 2015,77 (1) : 161-170. DOI : 10.1007/s00027-014-0377-0.

[108] Latrubesse EM, Arima EY, Dunne T et al. Damming the rivers of the Amazon basin. Nature, 2017, 546( 7658 ) : 363 369. DOI: $10.1038 /$ nature22333.

[109] Xie P. Ecological impacts of Three Gorges Dam on lakes Dongting and Poyang. Resources and Environment in the Yangtze Basin, 2017, 26(10): 1607-1618. [谢平. 三峡工程对两湖的生态影响. 长江流域资源与环境, 2017, 26(10): 1607-1618.]

[110] Xu XL. Research on ecohydrological processes in a typical deltal wetland in Poyang Lake [Dissertation]. Beijing: The University of Chinese Academy of Sciences, 2015. [许秀丽. 鄱阳湖典型洲滩湿地生态水文过程研究 [学位论文]. 北 京: 中国科学院大学, 2015.]

[111] Conant B Jr, Robinson CE Jr, Hinton MJ Jr et al. A framework for conceptualizing groundwater-surface water interactions and identifying potential impacts on water quality, water quantity, and ecosystems. Journal of Hydrology, 2019, 574: 609627. DOI: 10.1016/j.jhydrol.2019.04.050.

[112] Liu D, Wang X, Li CH et al. Eco-environmental effects of hydrological connectivity on lakes: A review. Resources and Environment in the Yangtze Basin, 2019, 28(7): 1702-1715. [ 刘丹, 王烜, 李春晖等. 水文连通性对湖泊生态环境影响 的研究进展. 长江流域资源与环境, 2019, 28(7): 1702-1715.]

[113] Lallias-Tacon S, Liébault F, Piégay H. Use of airborne LiDAR and historical aerial photos for characterising the history of braided river floodplain morphology and vegetation responses. CATENA, 2017, 149: 742-759. DOI : 10.1016/j. catena. 2016.07.038.

[114] Zhang GX ed. Wetland ecological hydrology and water resources management. Beijing: Science Press, 2014. [ 章光新. 湿 地生态水文与水资源管理. 北京: 科学出版社, 2014.]

[115] Xiao DR, Zhang C, Tian K et al. Development of alpine wetland vegetation and its effect on carbon sequestration after dam construction: A case study of Lashihai in the northwestern Yunnan plateau in China. Aquatic Botany, 2015, 126: 16-24. DOI : $10.1016 /$ j.aquabot.2015.06.001.

[116] Søndergaard M, Johansson LS, Lauridsen TL et al. Submerged macrophytes as indicators of the ecological quality of lakes. Freshwater Biology, 2010, 55(4) : 893-908. DOI : 10.1111/j.1365-2427.2009.02331.x.

[117] Feng L, Han XX, Hu CM et al. Four decades of wetland changes of the largest freshwater lake in China: Possible linkage to the Three Gorges Dam? Remote Sensing of Environment, 2016, 176: 43-55. DOI: 10.1016/j.rse.2016.01.011.

[118] Kellogg CH, Bridgham SD, Leicht SA. Effects of water level, shade and time on germination and growth of freshwater marsh plants along a simulated successional gradient. Journal of Ecology, 2003, 91(2) : 274-282. DOI: 10.1046/j.13652745.2003.00764.x.

[119] Raulings EJ, Morris K, Roache MC et al. The importance of water regimes operating at small spatial scales for the diversity and structure of wetland vegetation. Freshwater Biology, 2010, 55 (3) : 701-715. DOI: 10. 1111/j. 1365-2427. 2009. 
02311.x.

[120] Sher AA, Marshall DL. Seedling competition between native Populus deltoides (Salicaceae) and exotic Tamarix ramosissima (Tamaricaceae) across water regimes and substrate types. American Journal of Botany, 2003, 90(3) : 413-422. DOI: $10.3732 /$ ajb.90.3.413.

[121] Wolfe BE, Weishampel PA, Klironomos JN. Arbuscular mycorrhizal fungi and water table affect wetland plant community composition. Journal of Ecology, 2006, 94(5) : 905-914. DOI: 10.1111/j.1365-2745.2006.01160.x.

[122] Ghorbanalizadeh A, Akhani H, Bergmeier E. Vegetation patterns of a rapidly drying up salt lake ecosystem: Lake Urmia, NW Iran. Phytocoenologia, 2020, 50(1) : 1-46. DOI: 10.1127/phyto/2019/0338.

[123] Lishawa SC, Albert DA, Tuchman NC. Water level decline promotes Typha X glauca establishment and vegetation change in Great Lakes coastal wetlands. Wetlands, 2010, 30(6) : 1085-1096. DOI : 10.1007/s13157-010-0113-z.

[124] Casanova MT, Brock MA. How do depth, duration and frequency of flooding influence the establishment of wetland plant communities?. Plant Ecology, 2000, 147(2) : 237-250. DOI: 10.1023/A: 1009875226637.

[125] Wilcox DA, Nichols SJ. The effects of water-level fluctuations on vegetation in a Lake Huron wetland. Wetlands, 2008,28 (2) : 487-501. DOI: 10.1672/07-129.1.

[126] Toogood SE, Joyce CB. Effects of raised water levels on wet grassland plant communities. Applied Vegetation Science, 2009, 12(3) : 283-294. DOI: 10.1111/j.1654-109X.2009.01028.x.

[127] Stromberg JC, Tiller R, Richter B. Effects of groundwater decline on riparian vegetation of semiarid regions: The San Pedro, Arizona. Ecological Applications, 1996, 6(1) : 113-131. DOI : 10.2307/2269558.

[128] Magee TK, Kentula ME. Response of wetland plant species to hydrologic conditions. Wetlands Ecology and Management, 2005, 13(2) : 163-181. DOI: 10.1007/s11273-004-6258-x.

[129] Chapin DM, Paige DK. Response of delta vegetation to water level changes in a regulated mountain lake, Washington State, USA. Wetlands, 2013, 33(3) : 431-444. DOI: 10.1007/s13157-013-0401-5.

[130] Todd MJ, Muneepeerakul R, Pumo D et al. Hydrological drivers of wetland vegetation community distribution within Everglades National Park, Florida. Advances in Water Resources, 2010, 33(10) : 1279-1289. DOI : 10.1016/j.advwatres.2010. 04.003 .

[131] Pollock MM, Naiman RJ, Hanley TA. Plant species richness in riparian wetlands-a test of biodiversity theory. Ecology, 1998, 79(1) : 94-105. DOI: 10.1890/0012-9658 (1998) 079[0094: PSRIRW ]2.0.CO;2.

[132] Odland A, del Moral R. Thirteen years of wetland vegetation succession following a permanent drawdown, Myrkdalen Lake, Norway. Plant Ecology, 2002, 162(2) : 185-198. DOI: 10.1023/A : 1020388910724.

[133] Toner M, Keddy P. River hydrology and riparian wetlands: A predictive model for ecological assembly. Ecological Applications, 1997, 7(1) : 236-246. DOI: 10.1890/1051-0761 (1997) 007[0236: RHARWA ]2.0.CO;2.

[134] Booth EG, Loheide SP. Comparing surface effective saturation and depth-to-water-level as predictors of plant composition in a restored riparian wetland. Ecohydrology, 2012, 5(5) : 637-647. DOI: 10.1002/eco.250.

[135] Valdez JW, Hartig F, Fennel S et al. The recruitment niche predicts plant community assembly across a hydrological gradient along plowed and undisturbed transects in a former agricultural wetland. Frontiers in Plant Science, 2019, 10: 88. DOI: $10.3389 /$ fpls.2019.00088.

[136] Yang ZF ed. Mechanism, model and allocation of ecological water requirement in wetlands. Beijing: Science Press, 2012. [ 杨志峰. 湿地生态需水机理、模型和配置. 北京: 科学出版社, 2012.]

[137] Naumburg E, Mata-Gonzalez R, Hunter RG et al. Phreatophytic vegetation and groundwater fluctuations: A review of current research and application of ecosystem response modeling with an emphasis on Great Basin vegetation. Environmental Management, 2005, 35(6) : 726-740. DOI : 10.1007/s00267-004-0194-7.

[138] Ridolfi L, D'Odorico P, Laio F. Effect of vegetation-water table feedbacks on the stability and resilience of plant ecosystems. Water Resources Research, 2006, 42(1): W01201. DOI: 10.1029/2005WR004444.

[139] Pagter M, Bragato C, Brix H. Tolerance and physiological responses of Phragmites australis to water deficit. Aquatic Bota$n y, 2005,81(4)$ : 285-299. DOI: 10.1016/j.aquabot.2005.01.002.

[140] Zhou YX. A review of research methodologies of groundwater dependent terrestrial vegetations. Earth Science Frontiers, 2010, 17(6) : 21-30. [周仰效. 地下水-陆生植被系统研究评述. 地学前缘, 2010, 17(6) : 21-30.]

[141] Gong L, Zhang LL, Zhou LZ et al. Bird diversity in summer in Anqing floodplain wetlands, middle-lower reaches of the 
Yangtze River. J Lake Sci, 2013, 25(6) : 872-882. DOI: 10.18307/2013.0611. [宫蕾, 张黎黎, 周立志等. 长江中下 游安庆沿江湖泊湿地夏季鸟类多样性调查. 湖泊科学, 2013, 25(6) : 872-882.]

[142] Tang XG, Li HP, Xu XB et al. Changing land use and its impact on the habitat suitability for wintering Anseriformes in China's Poyang Lake region. Science of the Total Environment, 2016, 557/558: 296-306. DOI: 10.1016/j.scitotenv.2016. 03.108 .

[143] Warnock N, Haig SM, Oring LW. Monitoring species richness and abundance of shorebirds in the western Great Basin. The Condor, 1998, 100(4) : 589-600. DOI: 10.2307/1369741.

[144] Barnum DA, Bradley T, Cohen M et al. State of the Salton Sea-A science and monitoring meeting of scientists for the Salton Sea: U.S. Geological Survey Open-File Report 2017-1005, 2017: 20.

[145] Bradley TJ, Yanega GM. Salton Sea: Ecosystem in transition. Science, 2018, 359 (6377) : 754. DOI: 10. 1126/ science.aar6088.

[146] Ji WT, Zeng NJ, Wang YB et al. Analysis on the waterbirds community survey of Poyang lake in winter. Geographic Information Sciences, 2007, 13(1/2) : 51-64. DOI: 10.1080/10824000709480632.

[147] Matthews S, O'Connor R, Plantinga AJ. Quantifying the impacts on biodiversity of policies for carbon sequestration in forests. Ecological Economics, 2002, 40(1) : 71-87. DOI: 10.1016/S0921-8009(01)00269-5.

[148] Wu JG, Lv JJ. Effects of land use change on the biodiversity. Ecology and Environment, 2008, 17(3) : 1276-1281. [吴 建国，吕佳佳.土地利用变化对生物多样性的影响. 生态环境, 2008, 17(3)：1276-1281.]

[149] Steen VA, Skagen SK, Melcher CP. Implications of climate change for wetland-dependent birds in the prairie pothole region. Wetlands, 2016, 36(2) : 445-459. DOI : 10.1007/s13157-016-0791-2.

[150] Iknayan KJ, Beissinger SR. Collapse of a desert bird community over the past century driven by climate change. Proceedings of the National Academy of Sciences, 2018, 115(34): 8597-8602.

[151] Haig SM, Murphy SP, Matthews JH et al. Climate-altered wetlands challenge waterbird use and migratory connectivity in arid landscapes. Scientific Reports, 2019, 9: 4666. DOI: 10.1038/s41598-019-41135-y.

[152] Donnelly JP, King SL, Silverman NL et al. Climate and human water use diminish wetland networks supporting continental waterbird migration. Global Change Biology, 2020, 26(4) : 2042-2059. DOI: 10.1111/gcb.15010.

[153] Xia SX, Liu Y, Wang YY et al. Wintering waterbirds in a large river floodplain: Hydrological connectivity is the key for reconciling development and conservation. Science of the Total Environment, 2016, 573: 645-660. DOI : 10.1016/j.scitotenv.2016.08.147.

[154] Li YK, Qian FW, Silbernagel J et al. Community structure, abundance variation and population trends of waterbirds in relation to water level fluctuation in Poyang Lake. Journal of Great Lakes Research, 2019, 45(5) : 976-985. DOI: 10.1016/ j.jglr.2019.08.002.

[155] Zhao KY, Lou YJ, Hu JM et al. A study of current status and conservation of threatened wetland ecological environment in Sanjiang Plain. Journal of Natural Resources, 2008, 23(5): 790-796. [赵魁义, 娄彦景, 胡金明等. 三江平原湿地生 态环境受威胁现状及其保育研究. 自然资源学报, 2008, 23(5) : 790-796. $]$

[156] Wetlands International-China Programme ed. Wetland and waterbird conservation. Beijing: China Forestry Publishing House, 1998. [湿地国际-中国项目办事处. 湿地与水禽保护. 北京: 中国林业出版社, 1998.]

[157] Vanausdall RA, Dinsmore SJ. Habitat associations of migratory waterbirds using restored shallow lakes in Iowa. Waterbirds, 2019, 42(2) : 135. DOI: 10.1675/063.042.0201.

[158] Zhang SX, Wang RX, Shen JX et al. Potential relationship of wintering waterbirds community composition and water-level fluctuation in Lake Erhai. Asian Journal of Ecotoxicology, 2018, 13(4) : 143-148. [张淑霞, 王荣兴, 沈建新等. 洱海 冬季水鸟群落结构与水位变化的潜在关系. 生态毒理学报, 2018, 13(4): 143-148. ]

[159] Lane CR, Leibowitz SG, Autrey BC et al. Hydrological, physical, and chemical functions and connectivity of non-floodplain wetlands to downstream waters: A review. JAWRA Journal of the American Water Resources Association, 2018,54 (2) : 346-371. DOI : $10.1111 / 1752-1688.12633$.

[160] Zhu GW, Zou W, Guo CX et al. Long-term variations of phosphorus concentration and capacity in Lake Taihu, 20052018: Implications for future phosphorus reduction target management. J Lake Sci, 2020, 32(1) : 21-35. DOI: 10.18307/ 2020.0103. [ 朱广伟, 邹伟, 国超旋等. 太湖水体磷浓度与赋存量长期变化(2005-2018 年) 及其对未来磷控制目 标管理的启示. 湖泊科学, 2020, 32(1): 21-35.] 
[161] Zhai SH, Han T, Chen F. Self-purification capacity of nitrogen and phosphorus of Lake Taihu on the basis of mass balance. J Lake Sci, 2014, 26(2) : 185-190. DOI: 10.18307/2014.0203. [翟淑华, 韩涛, 陈方. 基于质量平衡的太湖 氮、磷自净能力计算. 湖泊科学, $2014,26(2): 185-190$. ]

[162] Kelderman P, Wei Z, Maessen M. Water and mass budgets for estimating phosphorus sediment-water exchange in Lake Taihu (China P. R.). Hydrobiologia, 2005, 544(1) : 167-175. DOI: 10.1007/s10750-005-0542-5.

[163] Xu PZ, Qin BQ. Water quantity and pollutant fluxes of the surrounding rivers of Lake Taihu during the hydrological year of 2001-2002. J Lake Sci , 2005, 17(3) : 213-218. DOI : 10.18307/2005.0304. [许朋柱, 秦伯强. 20012002 水文年环太 湖河道的水量及污染物通量. 湖泊科学, 2005, 17(3): 213-218.]

[164] Ogwada RA, Reddy KR, Graetz DA. Effects of aeration and temperature on nutrient regeneration from selected aquatic macrophytes. Journal of Environmental Quality, 1984, 13(2) : 239-243. DOI: 10.2134/jeq1984.00472425001300020013x.

[165] Qian LW, Duan H, Yan JF et al. Can multiple harvests of plants improve nitrogen removal from the point-bar soil of lake?. Journal of Environmental Management, 2019, 249: 109371. DOI: 10.1016/j.jenvman.2019.109371.

[166] Hopkins KG, Noe GB, Franco F et al. A method to quantify and value floodplain sediment and nutrient retention ecosystem services. Journal of Environmental Management, 2018, 220: 65-76. DOI: 10.1016/j.jenvman.2018.05.013.

[167] Mitsch WJ. Wetlands and lakes as nitrogen traps. Ecological Engineering, 1995, 5(1) : 123-125. DOI : 10.1016/09258574( 95 ) 90014-4.

[168] Harrison JA, Maranger RJ, Alexander RB et al. The regional and global significance of nitrogen removal in lakes and reservoirs. Biogeochemistry, 2009, 93(1/2) : 143-157. DOI: 10.1007/s10533-008-9272-x.

[169] Bettez ND, Groffman PM. Denitrification potential in stormwater control structures and natural riparian zones in an urban landscape. Environmental Science \& Technology, 2012, 46(20) : 10909-10917. DOI: 10.1021/es301409z.

[170] Wang Y, Shen ZY, Niu JF et al. Adsorption of phosphorus on sediments from the Three-Gorges Reservoir (China) and the relation with sediment compositions. Journal of Hazardous Materials, 2009, 162 (1) : 92-98. DOI: 10.1016/j.jhazmat. 2008.05.013.

[171] Jin XC, Wang SR, Pang Y et al. The adsorption of phosphate on different trophic lake sediments. Colloids and Surfaces A: Physicochemical and Engineering Aspects, 2005, 254(1/2/3) : 241-248. DOI: 10.1016/j.colsurfa.2004.11.016.

[172] Pant HK, Reddy KR. Phosphorus sorption characteristics of estuarine sediments under different redox conditions. Journal of Environmental Quality, 2001, 30(4) : 1474-1480. DOI : 10.2134/jeq2001.3041474x.

[173] Hu ZT, Sun HW, Tan Y. Adsorptive characteristic of nutrient elements and influential factors in Taihu Lake sediment. Journal of Agro-Environmental Science, 2004, 23(6) : 1212-1216. [胡智㢷, 孙红文, 谭媛. 湖泊沉积物对 N 和 P 的 吸附特性及影响因素研究. 农业环境科学学报, 2004, 23(6): 1212-1216.]

[174] Yang CM, Jing YC, Shen S et al. Effects of fine bubble aeration and capping on the distributions of phosphorus forms and release potential in the sediment from a heavily polluted urban river. Environmental Chemistry, 2015, 34(6) : 1150-1157. [杨长明, 荆亚超, 沈炼等. 微孔曝气与覆盖对城市重污染河道底泥磷形态分布及释放过程的影响. 环境化学, 2015, 34(6) : 1150-1157.]

[175] Shaheen SM, Abdelrazek MAS, Elthoth M et al. Potentially toxic elements in saltmarsh sediments and common reed (Phragmites australis) of Burullus coastal lagoon at North Nile Delta, Egypt: A survey and risk assessment. Science of the Total Environment, 2019, 649: 1237-1249. DOI: 10.1016/j.scitotenv.2018.08.359.

[176] Bonanno G, Borg JA, Di Martino V. Levels of heavy metals in wetland and marine vascular plants and their biomonitoring potential: A comparative assessment. Science of the Total Environment, 2017, 576: 796-806. DOI: 10.1016/j.scitotenv. 2016.10.171.

[177] Galal TM, Gharib FA, Ghazi SM et al. Metal uptake capability of Cyperus articulatus L. and its role in mitigating heavy metals from contaminated wetlands. Environmental Science and Pollution Research, 2017, 24(27): 21636-21648. DOI: $10.1007 / \mathrm{s} 11356-017-9793-8$. 